\title{
Mineralogy and evolution of the surface of Mars: A review
}

\author{
V. Chevrier ${ }^{\mathrm{a}, \mathrm{b}, *}$, P.E. Mathé \\ ${ }^{a}$ Arkansas Center for Space and Planetary Science, 202 Old Museum Building, University of Arkansas, Fayetteville, AR 72701, USA \\ ${ }^{\mathrm{b}}$ CEREGE, Europôle Méditerranéen de l'Arbois, BP80, 13545 Aix-en-Provence Cedex 04, France
}

Accepted 30 May 2006

\begin{abstract}
We review the mineralogy of the surface of Mars, using data from various sources, including in situ characterisations performed by landers, remote observations from orbit, and studies of the SNC meteorites. We also discuss the possible alteration processes and the factor controlling them, and try to relate the mineralogical observations to the chemical evolution of the surface materials on Mars in order to identify the dominant process(es). Then we try to describe a possible chemical and mineralogical evolution of the surface materials, resulting from weathering driven by the abundance and activity of water. Even if weathering is the dominant process responsible for the surface evolution, all observations suggest that it is strongly affected locally in time and space by various other processes including hydrothermalism, volcanism, evaporites, meteoritic impacts and aeolian erosion. Nevertheless, the observed phases on the surface of Mars globally depend on the evolution of the weathering conditions. This hypothesis, if confirmed, could give a new view of the evolution of the martian surface, roughly in three steps. The first would correspond to clay-type weathering process in the Noachian, under a probable thick $\mathrm{H}_{2} \mathrm{O} / \mathrm{CO}_{2}$-rich atmosphere. Then, during the Hesperian when water became scarcer and its activity sporadic, linked to volcanic activity, sulfate-type acidic weathering process would have been predominant. The third period would be like today, a very slow weathering by strongly oxidising agents $\left(\mathrm{H}_{2} \mathrm{O}_{2}, \mathrm{O}_{2}\right)$ in cold and dry conditions, through solid-gas or solid-films of water resulting frost-thaw and/or acid fog. This would favour poorly crystalline phases, mainly iron (oxy) hydroxides. But in this scenario many questions remain about the transition between these processes, and about the factors affecting the evolution of the weathering process.
\end{abstract}

(C) 2006 Elsevier Ltd. All rights reserved.

Keywords: Mars; Surface; Mineralogy; Weathering; Alteration; Iron (oxy)hydroxides; Clays; Sulfates; Carbonates; Silicates

\section{Introduction}

Our objective is to provide an overview as complete as possible of our current knowledge of the martian regolith mineralogy, and its evolution with time. Classically, the regolith of a planet is defined as the uppermost surface layer, composed of unconsolidated erratic rocky blocks of various sizes and the associated dust particles, which result from meteoritic bombardment. This definition lacks in the explaination of the red colour of Mars, an obvious indicator of surface alteration. In the case of a complex planetary surface like that of Mars, the regolith is not only the uppermost dust layer covering the surface-including

\footnotetext{
*Corresponding author. Tel.: + 14795753170.

E-mail addresses: vchevrie@uark.edu,chevrier@cerege.fr (V. Chevrier), mathe@cerege.fr (P.E. Mathé).
}

rock varnish-but also the underlying horizons, from partially altered but still coherent rocks, the so-called "saprolitic" horizons, down to the fresh parent rock. Therefore, the characterisation of the martian regolith involves not only the primary materials but also the minerals produced by the various processes occurring on the surface. Several approaches have been used, each giving complementary information. First there are direct measurements by spacecraft that have orbited (Mariner 9, the Viking Orbiters, Phobos 2, Mars Global Surveyor, Mars Odyssey, Mars Express) and landed on Mars (Viking Landers 1 and 2, Mars Pathfinder and Mars Exploration Rovers MER, Spirit and Opportunity, Fig. 1). Second, there are many petrologic, mineralogical, chemical and isotopic studies of the martian SNC meteorites. Third, there are laboratory measurements on analogue materials that have proven especially valuable in identifying models 


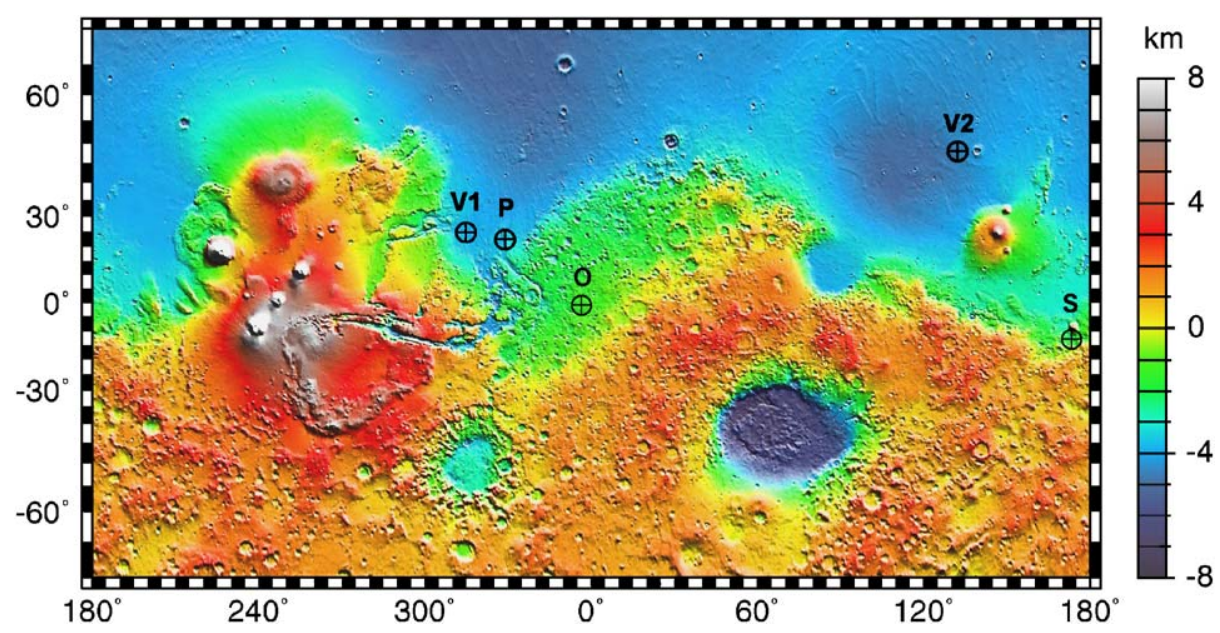

Fig. 1. Topographic image in false colours of the martian surface, generated with MOLA (Mars Orbiter Laser Altimeter) onboard Mars Global Surveyor. Symbols correspond to the various martian landers: V1: Viking 1, V2: Viking 2, P: Mars Pathfinder, O: MER Opportunity, S: MER Spirit. Credit: NASA/ GSFC—http://ltpwww.gsfc.nasa.gov/tharsis/global_paper.html, Smith et al., 1999.

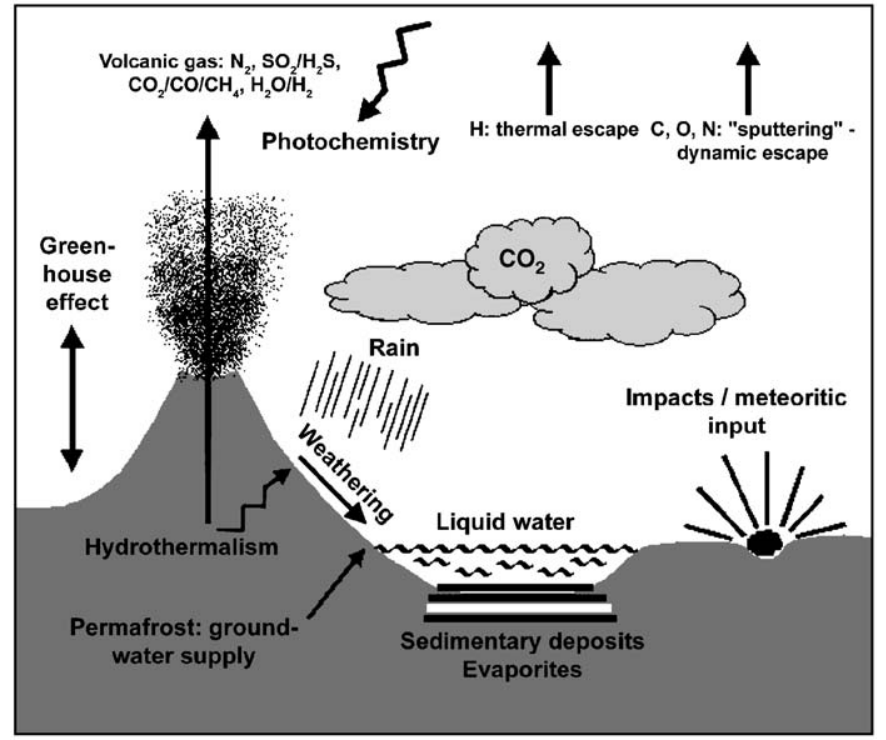

Fig. 2. Geodynamical environment on Early Mars (redrawn from Catling, 1999).

and interpreting direct observations from spacecraft. Somewhat related are studies of terrestrial analogues that can represent certain processes likely to occur on Mars. In parallel with laboratory measurements are theoretical studies of the thermodynamics of equilibrium assemblages on the martian surface. By the combination of these approaches it is possible to make reasonable assumptions on the complex mineralogy of the martian surface, and how the parageneses formed and evolved with time.

Therefore, in a second part of this paper we discuss the various processes susceptible to have altered the surface of Mars, depending on the prevailing geodynamical environment (Fig. 2). Generally, all hypotheses can be roughly classified in three main alteration processes: aqueous alteration and evaporitic process, hydrothermalism and weathering. Basically, the aqueous alteration is mainly linked to Opportunity discovery of sedimentary outcrops in Meridiani Planum, and sulfate deposits by Mars Express OMEGA. It supposes formation of salts by acidic alteration with subsequent deposition due to evaporation of a body of standing water. Hydrothermalism comes from SNC studies, chemistry of the regolith and its link to the volcanic activity which seems to be an important driving force for the evolution of the surface. Both of these processes remain generally localised in time and space. Finally we test the weathering hypothesis, which is defined by the interaction between primary bedrock, the surrounding atmosphere, the hydrosphere and the biosphere, leading to the formation of a regolith. In this case, weathering is able to act during the whole history of the planet as well as on its whole surface, depending on the evolution of the atmosphere/hydrosphere.

\section{Mineralogy of the martian surface}

\subsection{Primary silicates}

The silicates are the most abundant minerals on the surface of the telluric planets. On Mars, the primary silicate paragenesis is of basaltic to andesitic basaltic composition, as indicated by orbital observations by Mars Global Surveyor MGS and Mars Odyssey (Hamilton et al., 2003; Wyatt and McSween, 2002; Wyatt and McSween, 2003), in situ characterisations performed by the Viking Landers and Mars Pathfinder (Larsen et al., 2000; McSween et al., 1999) as well as studies on the SNC meteorites (McSween, 2002). The main silicates observed on the surface are olivine pyroxene and plagioclase, although recent evidence for silica-rich quartzo-feldspathic minerals (Bandfield et al., 2004) seems to indicate that magmatic differentiation may have proceed further than previously thought. Olivine, pyroxene and plagioclase have been identified and mapped 
by Mars Global Surveyor Thermal Emission Spectrometer MGS-TES (Bandfield, 2002), by Mars Odyssey Thermal Emission Imaging System THEMIS (Christensen et al., 2003; Hamilton and Christensen, 2005) and Mars Express Observatoire pour la Mineralogie, l'Eau, les Glaces et l'Activité OMEGA (Bibring et al., 2005). MGS-TES has also detected plagioclase on Mars (Hamilton et al., 2001), although recent studies suggest that spectra can be better fitted if including shocked plagioclase resulting from meteoritic impacts (Johnson et al., 2006). Olivine and pyroxene have also been observed in situ by the mini-TES and Mössbauer spectrometers on the Mars Exploration Rovers (McSween et al., 2006). In addition to the basaltic rocks, these phases are also present in the soil (basaltic sand) at both landing sites of Gusev Crater and Meridiani Planum (Klingelhöfer et al., 2004b; Morris et al., 2004). However, olivine is extremely widespread in Gusev Crater, in relatively high concentrations similar to those present in olivine-phyric shergottites (McSween et al., 2006). According to THEMIS observations, the largest deposit of olivine is in Nili Fossae (Christensen et al., 2003; Hamilton and Christensen, 2005; Hoefen et al., 2003). Mars Express OMEGA observations indicate that olivine is generally present in some restricted areas, like rims and floors of craters (Mustard et al., 2005). Two types of pyroxene have been spectrally confirmed in the south crust on Mars (type I terrains in TES mapping, Fig. 3): high calcium pyroxene (HCP or clinopyroxene) is present in Hesperian terrains of
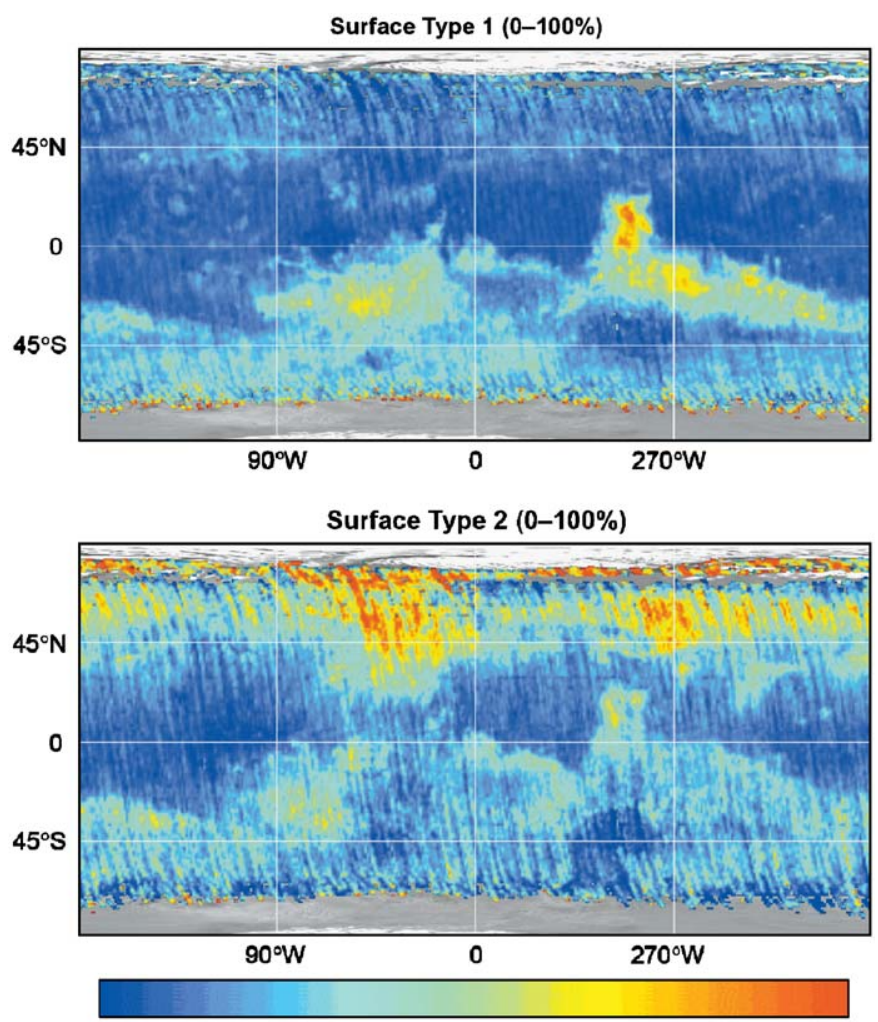

Fig. 3. Global area concentrations of surface types I and II. Ranges in parentheses give the lowest unit (blue) to the highest unit (red) on the scale bar. Source of the picture: Bandfield et al. (2000). low-albedo while low calcium pyroxene (LCP or orthopyroxene) is mainly present in bright terrains of Noachian age (Bibring et al., 2005; Mustard et al., 2005). However, in general both types of pyroxenes co-exist. The northern crust of Mars (the type II terrain identified by TES data, Fig. 3) does not present any clear signal in Mars Express spectra (Mustard et al., 2005). TES data of these zones have been interpreted as resulting from the presence of silica-rich andesitic basalt (Bandfield et al., 2000; Hamilton et al., 2001). Alternatively, altered basalts enriched in phyllosilicates (Wyatt and McSween, 2002; Wyatt et al., 2004) could also explain the observations, even if it seems that phyllosilicates alone are not sufficient to describe the TES spectra (Michalski et al., 2005), that a silica rich component such as zeolites or pure silica must be taken in consideration, and that altered shergottites do not provide a very good TES analogue of these terrains (Hamilton and Minitti, 2003). The presence of pure silica has also been inferred from geochemical modelling and mobility of elements during weathering of primary olivine and pyroxene (McLennan, 2003). Models of mineralogical composition show also that Meridiani Planum outcrops should contain about $20 \mathrm{wt} \%$ of amorphous silica (Clark et al., 2005). Zeolites, which are hydrated silicates, are invoked as possible reservoirs of water on the surface of Mars (Bish et al., 2003; Fialips et al., 2005; Tokano and Bish, 2005). However, no observation has confirmed their presence on the surface of Mars.

\subsection{Phyllosilicates}

Phyllosilicates (clay minerals, serpentine and talc) are phases that typically result from alteration of primary silicates in the presence of water. The main phyllosilicates expected to be present on Mars are the iron-rich members: minnesotaite $\left(\mathrm{Fe}^{2+}, \mathrm{Mg}\right)_{3} \mathrm{Si}_{4} \mathrm{O}_{10}(\mathrm{OH})_{2}$ (talc group) which is a product of fayalite (olivine) weathering under martian conditions (Gooding, 1978) or greenalite $\left(\mathrm{Fe}^{2+}, \mathrm{Fe}^{3+}\right)_{2-3} \mathrm{Si}_{2} \mathrm{O}_{5}(\mathrm{OH})_{4}$ (serpentine group) which is a silicate phase in equilibrium with siderite, depending on the $\mathrm{CO}_{2}$ partial pressure, presumed to be present in the primitive alteration assemblages (Catling, 1999; Ohmoto et al., 2004), but none of these phase has been observed on Mars. Clays have been assumed to be present on Mars since the first inorganic chemical analyses of Viking (Toulmin et al., 1977). Arguments based on terrestrial analogues, especially palagonitised tephras, have also suggested that various clays of the smectite group are present on Mars, including nontronite $\mathrm{Na}_{0.3} \mathrm{Fe}_{2}^{3+}(\mathrm{Si}$, $\mathrm{Al})_{4} \mathrm{O}_{10}(\mathrm{OH})_{2} . n \mathrm{H}_{2} \mathrm{O}$ and montmorillonite $(\mathrm{Na}, \mathrm{Ca})_{0.33}(\mathrm{Al}$, $\mathrm{Mg})_{2} \mathrm{Si}_{4} \mathrm{O}_{10}(\mathrm{OH})_{2} \cdot n \mathrm{H}_{2} \mathrm{O}$ (Banin et al., 1993; Bishop et al., 1995; Gooding and Keil, 1978; Singer, 1981; Singer, 1982). Following the results of Viking landers, some studies have lalso suggested that shocked/heated nontronite could explain the red colour and magnetic properties of the Martian fines (Boslough et al., 1986; Moskowitz and Hargraves, 1984; Weldon et al., 1982). The presence of clays on Mars has also been inferred from the observation of complex associations of 
Table 1

Summary of iron oxides and (oxy)hydroxides and their relevance to the various properties studied by the landers on the surface of Mars

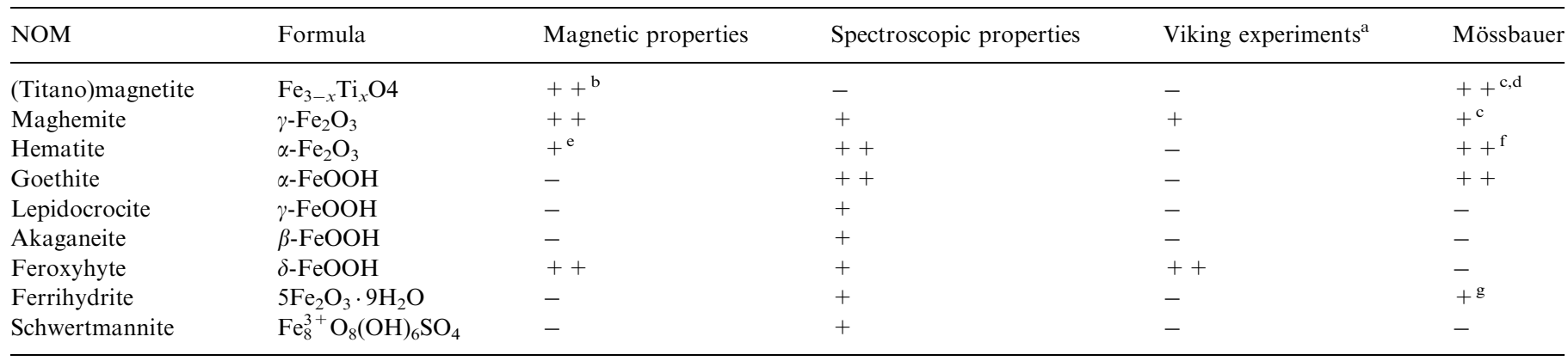

++ : very good accordance to data, $+:$ possible correspondence with a part of the data or the spectra, $-:$ no accordance.

References and discussion: see text.

${ }^{a}$ Oxidant and/or catalytic properties explaining the results of the biological experiments onboard Viking 1 and 2.

${ }^{\mathrm{b}}$ Magnetic properties strongly depend on the titanium content.

${ }^{c}$ Phase evidenced on the surface of some rocks, but the distinction between both phases is complicated.

${ }^{\mathrm{d}}$ Magnetite has been evidenced in the dust on the magnets.

${ }^{\mathrm{e}}$ Possible if considering the superparamagnetic nanocrystalline phase.

${ }^{\mathrm{f}}$ Valid only for the grey-crystalline variety, i.e. the berries.

${ }^{\mathrm{g}}$ Not directly evidenced but related to the quasi systematic presence of a paramagnetic nanophase.

clays and iron oxides (i.e. "iddingsite") in martian meteorites that have undergone preterrestrial alteration (Bridges et al., 2001; Bridges and Grady, 2000; Gillet et al., 2002). Clays are also present in Mini-TES deconvolution spectra of several outcrops in Meridiani Planum sedimentary deposits (Christensen et al., 2004b) and may be present in some rocks (Wooly Patch) of Gusev Crater (Wang et al., 2006b) on the basis of geochemical modelling and mass balance calculation (i.e. account for excess of silica and aluminium). Finally, clay minerals have been detected on the surface of Mars by Mars Express OMEGA infrared spectrometer (Poulet et al., 2005). These clays are mainly localised on the south Noachian crust. The best matches of spectral features are Fe-rich (nontronite), $\mathrm{Mg}$-rich (saponite) and Al-rich (montmorillonite) type clays. The presence of clays on the south crust may indicate specific climatic conditions in the Noachian, with more abundant liquid water (really abundant amounts lead to kaolinite) than required for the formation of sulphates in the conditions of the Hesperian (Poulet et al., 2005).

\subsection{Iron oxides and (oxy)hydroxides}

The iron phases were among the first proposed for the surface of Mars (Table 1) because the red colouration of the planet was attributed to them and because they are usually formed in alteration systems on the surface of the Earth (Schwertmann, 1985; Tardy and Nahon, 1985). Indeed, the Martian regolith contains about $20 \mathrm{wt} \% \mathrm{Fe}^{3+}$ (Bell III et al., 2000; Foley et al., 2003; Rieder et al., 1997) mostly under the form of iron oxides and (oxy)hydroxides. The various martian orbiters that have performed spectroscopic measurements in the infrared, the visible and the near UV have also provided evidence for various iron (oxy)hydroxides on the surface of Mars (Bell III et al., 1990; Morris et al., 2000). The main phases that have been identified are various forms of haematite (from the microcrystalline red variety (Morris et al., 1997; Morris et al., 1993), to the grey crystalline specular type (Christensen et al., 2000)) and goethite (Kirkland and Herr, 2000). The presence of these phases was confirmed by in situ measurements of Viking 1 and 2 Landers (Chryse Planitia and Utopia Planitia in 1976), Mars Pathfinder (Ares Vallis in 1997) and, finally, MER Spirit and Opportunity (in Gusev Crater and Meridiani Planum, respectively).

Reflectance and emission spectroscopy detect strongly coloured phases that absorb or reflect a specific wavelength. On the other hand, magnetic properties have also been used to detect strongly magnetic phases, such as spinel, that do not present a clear spectral signature (they may be considered "dark" phases). An array of magnets placed on the landers collects the dust carried by the wind while others have been pushed into the soil to collect the magnetic phases (Fig. 4, Hargraves et al., 1976a,b). Magnets of different strengths (the "capture" magnet and the "filter" magnet, Fig. 4) have been used to discriminate particles of different magnetic properties (Madsen et al., 2003). Spectrometric analyses by Mini-TES and Mössbauer then enable a fuller characterisation of the magnetic minerals. These experiments, performed by Viking (Hargraves et al., 1979, 1977), Pathfinder (Gunnlaugsson, 2000; Hviid et al., 1997; Madsen et al., 1999) and MER (Bertelsen et al., 2004; Madsen et al., 2003) showed that the martian soil is uniformly enriched in one or several strongly magnetic phases with saturation magnetisations ranging from 1 to $5 \mathrm{~A} \mathrm{~m}^{2} / \mathrm{kg}$ (Gunnlaugsson, 2000; Hviid et al., 1997), corresponding to $1-7 \%$ of the soil being magnetic minerals (Hargraves et al., 1979). The precise nature of the most strongly magnetic phase(s) remains presently unknown, though (titano)magnetite (1) and/or 


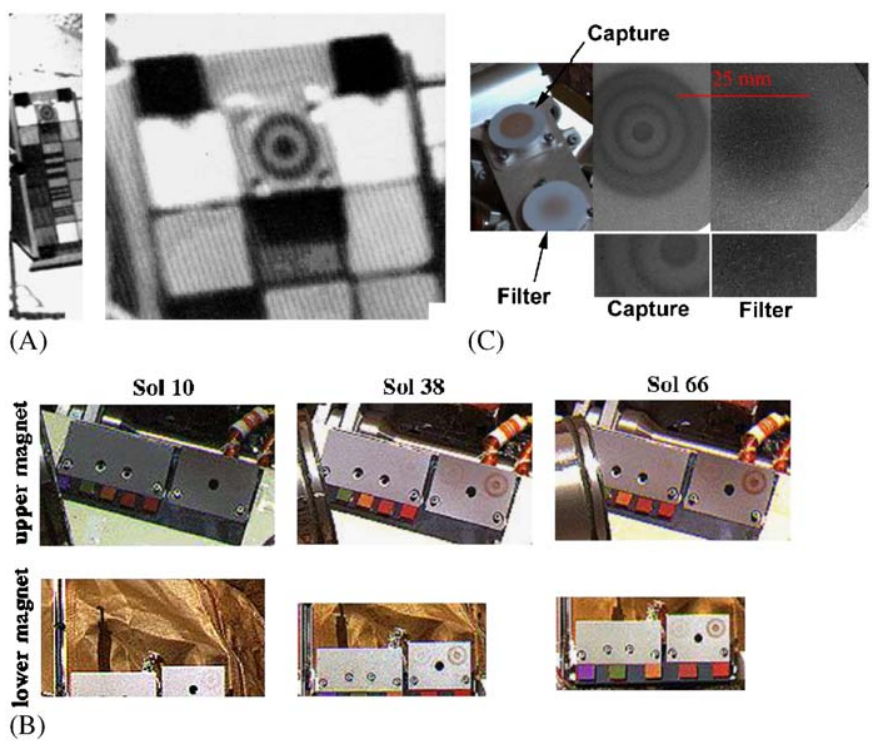

Fig. 4. Magnetic experiments onboard landers: (A): Viking lander 1. Magnetic array presenting a bull's-eye pattern indicating adhesion of magnetic particles - left: view of the colorimetric reference chart, right: zoom on the magnet. Source of the picture: Hargraves et al. (1976b). (B): Pathfinder experiments. Evolution of the amount of magnetic particles with time of exposition to the martian atmosphere. Credit: NASA, Hviid et al. (1997). (C): MER rovers magnetic experiments. Left: Pancam image of the capture and filter magnets, right: 4 images taken by the microscopic imager and showing relatively large particles probably resulting from agglomeration of smaller ones. Credit: NASA/JPL/ Cornell/USGS, http://marsrovers.jpl.nasa.gov/gallery/press/opportunity/ 20040305a/21-mm-03-dust-B041R1_br.jpg, Bertelsen et al. (2004).

maghemite (2) are generally favoured (Goetz et al., 2005; Hargraves et al., 1979, 1977; Madsen et al., 1999). The main difficulty is that the origin of the magnetic phases is unknown, whether they were either released from the parent rock (in this case assumption (1) would be favoured) or formed by alteration (favouring assumption (2)). It is also possible that the magnetic minerals are in complex assemblages such as clay minerals cemented by ferrimagnetic iron (oxy)hydroxides (Hargraves et al., 2000; Hviid et al., 1997). This latter idea is suggested by the rapid saturation of the magnets, implying a very abundant magnetic phase. Moreover, the intermediate value of saturation magnetisation, between haematite $\left(0.5 \mathrm{~A} \mathrm{~m}^{2} / \mathrm{kg}\right)$ and maghemite $\left(70 \mathrm{~A} \mathrm{~m}^{2} / \mathrm{kg}\right)$ suggests complex mineralogical assemblages, or even specific phases in terms of crystal chemistry.

The main innovation of the MER mission was to use Mössbauer spectroscopy (MIMOS) that could identify the iron bearing phases (Klingelhöfer et al., 1996, 2003). Due to its sensitivity to iron speciation, Mössbauer spectroscopy brings complementary information to the other spectroscopy techniques (Dyar and Scheafer, 2004; Wdowiak et al., 2003). With Mössbauer, it is possible to distinguish silicates (olivine, pyroxenes) from oxides (spinel, haematite, other (oxy)hydroxides) and other phases like the Fe-bearing sulphates. In that way, Mössbauer spectroscopy brought lot of information in the Opportu- nity site in Meridiani Planum where orbital analyses (MGS-TES) detected concentrations of crystalline haematite. Indeed, haematite spherules (Fig. 5) in association with ferric sulphates (jarosite), were found in evaporitic related outcrops (Squyres et al., 2004b). The other lander, Spirit in Gusev Crater, though showing formations more expected for the martian environment, has also found iron phases (Klingelhöfer et al., 2004a; Morris et al., 2004, 2006), indicating the presence of more or less amorphous nanophase, magnetically ordered iron (oxy)hydroxides (magnetite, haematite and goethite, Fig. 6), and $\mathrm{Fe}^{3+}$ sulphate.

Though not directly intended to study martian mineralogy, the various experiments performed by Viking 1 and 2 (pyrolitic release/carbon assimilation, gas exchange experiment and labeled release experiment) yielded insights into the mineralogy of the surface by discovering the unexpected chemical reactivity of the soil. Heating of samples of soil to $500{ }^{\circ} \mathrm{C}$ by the pyrolitic release experiment resulted in the formation of $\mathrm{CO}_{2}$ and $\mathrm{H}_{2} \mathrm{O}$, which was interpreted as resulting from the decomposition of phases such as sulphates, carbonates or (oxy)hydroxides such as goethite (Biemann et al., 1976). Wetting the soil caused the release of oxygen while the assimilation of ${ }^{14} \mathrm{C}$ marked nutriments induced the release of $\mathrm{CO}_{2}$ (Klein et al., 1976; Levin and Straat, 1976). These results suggested the presence of a strong oxidant (Ballou et al., 1978; Levin and Straat, 1976; Oyama et al., 1978; Yen et al., 2000), whose nature remains uncertain. Some authors attribute these experimental results to the presence of iron (oxy)hydroxides, like maghemite (Oyama et al., 1978), or exotic phases on Earth such as feroxyhyte (Burns, 1980a; Sherman et al., 1981) or even the family of the ferrates (Tsapin et al., 2000) containing iron(VI). The presence of such phases is not widely accepted, but their existence as minor phases remains a possibility.

\subsubsection{Haematite $\left(\alpha-\mathrm{Fe}_{2} \mathrm{O}_{3}\right)$}

Haematite is the iron oxide thought to be responsible for the colour of the surface of Mars (even if various other iron (oxy)hydroxides can also give Mars its "red" colour, which depends also strongly on the picture observed), although various morphologies are supposed to be present. Indeed, its occurrence is widespread in terrestrial alteration environments with various primary assemblages and thus haematite is a strong candidate of the surface mineralogy of Mars. It can be formed by hydrothermal processes (Catling and Moore, 2003; Wade et al., 1999), by palagonitisation (aqueous alteration at low temperature) of volcanic ashes or glass (Bishop et al., 1998a; Morris et al., 1993) and by meteoric weathering in tropical lateritic environments (Nahon, 1991; Schwertmann, 1985; Tardy and Nahon, 1985) or polar environments (Bender Koch et al., 1995). Furthermore, haematite is the only thermodynamically stable iron oxide in the present day martian conditions (Gooding, 1978) and constitutes the final product of many chemical and thermal transformation 


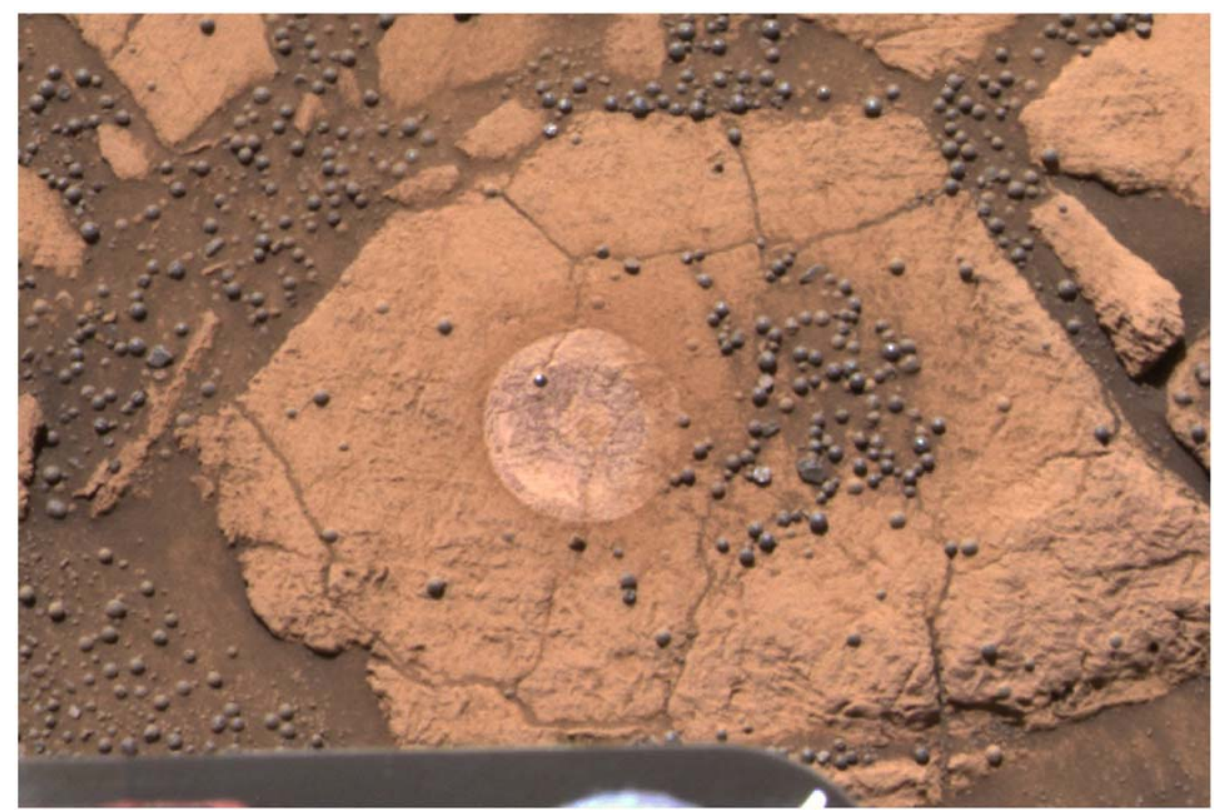

(A)
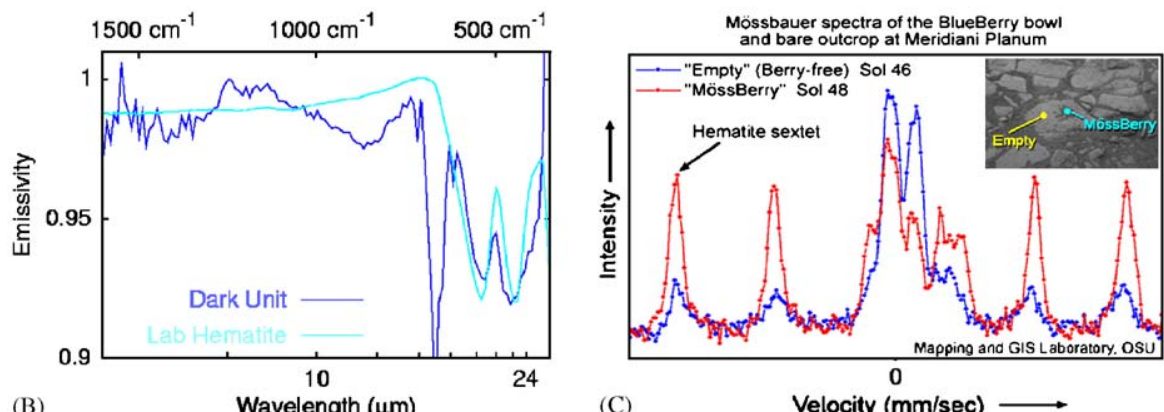

Fig. 5. Haematite berries on Mars. (A): Pancam picture of Berry bowl. The circular mark corresponds to brushing of the rock for comparison of Mössbauer spectra between a clear surface and a zone enriched in berries. Credit: NASA/JPL/Cornell. (B): Mini-TES spectrum of the haematite berries (lebeled "dark unit", compared with a laboratory spectra of haematite. Credit: NASA/JPL/Arizona University, http://marsrovers.jpl.nasa.gov/gallery/ press/opportunity/20040131a/dark_unit_lab_br.jpg, Christensen et al. (2004b). (C): Mössbauer spectra of the zones shown in the picture: the empty, brushed zone, and the zone enriched in berries, evidencing the sextet of haematite. Credit: NASA/JPL/Cornell/ University of Mainz, http:// marsrovers.jpl.nasa.gov/gallery/press/opportunity/20040318a/19-DR-01-graph-A074R1_br.jpg, Klingelhöfer et al. (2004b).

pathways of other oxides and (oxy)hydroxides (Barron and Torrent, 2002; Morris et al., 1998). Thus haematite is likely to be present on Mars with various crystallochemistries, depending on its origin. The first crystallochemical variety, identified on the MGS-TES spectra is the "grey and crystalline" haematite that forms large deposits of several hundreds of $\mathrm{km}^{2}$ in Terra Meridiani, Aram chaos, Candor Chasma and Ophir Chasma (Christensen et al., 2000; Lane et al., 2002). This haematite is always linked to stratified terrains, possibly of sedimentary origin (Hynek et al., 2002). The recent observations of MER Opportunity in Meridiani Planum confirmed the presence of crystalline haematite concretions ("blueberries", Fig. 5), identified by Mössbauer and mini-TES (Christensen et al., 2004b; Klingelhöfer et al., 2004b), and associated with sedimentary formations of evaporitic type in Meridiani Planum. It is highly probable that the haematite identified by MGSTES corresponds to the "blueberries" observed by MER
Opportunity, due to the common grey and crystalline character, by contrast with the very distinct others forms of haematite. The interpretation of these haematite deposits makes rise multiple hypothesises: precipitations in sedimentary environments from iron-rich waters (Baldridge and Calvin, 2004; Christensen et al., 2001) or organic solvents (Tang et al., 2006), alteration accompanied by dissolution/reprecipitation (Catling, 2004; Hynek et al., 2002), eventually favoured by hydrothermalism (Catling and Moore, 2003) or diagenesis (Ormö et al., 2004), deuteritic alteration of lava at the end of its crystallisation (Christensen et al., 2000; Minitti et al., 2004), or burying inducing a thermal transformation of pre-existing precursors (Glotch et al., 2003). Terrestrial analogues of Meridiani Planum berries, from Utah (Chan et al., 2004) or Hawai (Morris et al., 2005), suggest weathering and precipitation, eventually favoured by hydrothermalism. The microcrystalline red variety of haematite, typical of 


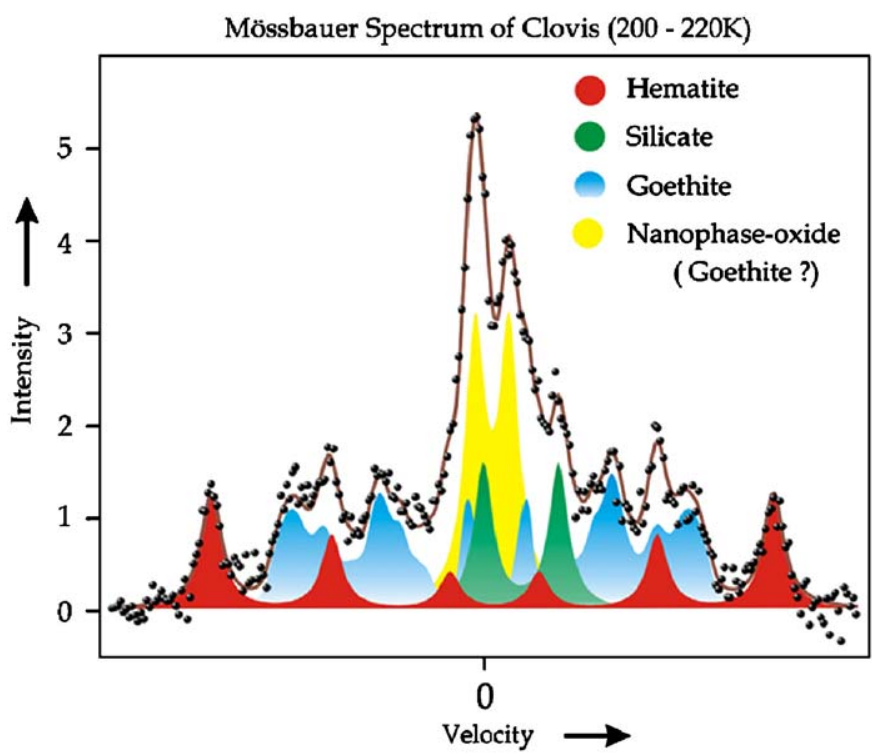

Fig. 6. Mössbauer spetrum of Clovis rock in Gusev Crater evidencing the association between goethite, haematite and $\mathrm{a} \mathrm{Fe}^{3+}$-bearing paramagnetic phase. Credit: NASA/JPL/University of Mainz, http://marsrovers. jpl.nasa.gov/gallery/press/spirit/20041213a/Mossbauer_Clovis-B313R1.jpg, Klingelhöfer et al. (2005).

terrestrial environments familiar to soil scientists, is often invoked to explain the spectra obtained by Mars Pathfinder (Morris and Golden, 1998; Morris et al., 1997). Superparamagnetic nanocrystalline haematite has even been supposed to explain the magnetic properties, providing a unique phase to describe all properties of the regolith (Morris et al., 1989). Finally haematite has also been found in the alteration assemblages studied by MER Spirit in Columbia Hills (Morris et al., 2006).

\subsubsection{Goethite $(\alpha-\mathrm{FeOOH})$}

Goethite, after haematite, was the second mineral identified on the surface of Mars by its spectroscopic properties (Kirkland and Herr, 2000; Morris and Golden, 1998; Morris et al., 2000). Goethite is frequently associated with haematite on Earth, in a variety of alteration pathways (Schwertmann, 1985). Recently, the MER Spirit Mössbauer spectrometer identified goethite in some altered outcrops (Clovis Rock) in Columbia Hills (Klingelhöfer et al., 2005; Morris et al., 2006), in association with haematite and a paramagnetic phase of unknown nature (Fig. 6). This provides the first in situ discovery of this phase on Mars. Haematite and goethite have also been identified in the martian meteorites showing traces of preterrestrial alteration (Bridges et al., 2001). Nevertheless, as goethite is antiferromagnetic (or sometimes very weakly ferrimagnetic), it can not account for the magnetic properties of the martian regolith. Additionally, goethite is not thermodynamically stable under present day conditions on Mars (Burns and Fisher, 1990c; Gooding, 1978). However, its formation in the primitive $\mathrm{H}_{2} \mathrm{O}$ and $\mathrm{CO}_{2}$-rich atmosphere is probable (Burns, 1988, 1993; Burns and
Fisher, 1990a, c; Chevrier et al., 2004). Thus very slow transformation kinetics can explain the presence of goethite, so that it is a long-timescale metastable phase (Burns and Fisher, 1993). Morphology and structure of the crystalline haematite formations, observed by MGS-TES suggest a deposit in aqueous media (Christensen et al., 2004a) with goethite as a probable precursor (Zolotov and Shock, 2005). This hypothesis has been confirmed by laboratory measurements indicating that the best analogue of the martian haematite spectra results from heated goethite (Glotch et al., 2004).

\subsubsection{Ferrihydrite $\left(5 \mathrm{Fe}_{2} \mathrm{O}_{3} \cdot 9 \mathrm{H}_{2} \mathrm{O}\right)$}

Ferrihydrite is a "quasi-amorphous" iron (oxy)hydroxide. The $2 \mathrm{~L}$ and $6 \mathrm{~L}$ ferrihydrites are defined according to the number of lines present on the X-ray diffraction patterns (Schwertmann and Cornell, 1991), indicating a crystalline order in specific crystallographic directions. This phase is not magnetic but represents a good candidate to explain some spectra acquired by Viking (Evans and Adams, 1980) and Pathfinder (McSween et al., 1999), especially when mixed with silicate phases. Ferrihydrite is also frequently detected in terrestrial analogues of the martian soil, and in particular in the palagonitised tephras (Bishop et al., 1998a, b, 1995; Evans and Adams, 1980). Furthermore, ferrihydrite is the usual precursor to crystalline phases, mainly haematite and goethite, depending on water activity, $\mathrm{pH}$, and temperature (Schwertmann, 1985; Schwertmann and Murad, 1983; Torrent et al., 1982). In liquid water, goethite formation is favoured at low temperatures and low $\mathrm{pH}$, whereas increasing temperatures and $\mathrm{pH}$ induce conversion into haematite (Schwertmann et al., 1999). Consequently, alteration in the today's anhydrous conditions of Mars may favour poorly crystalline (oxy)hydroxides, close to ferrihydrite (Banin, 1996; Banin et al., 1993; Bell III et al., 2000; Chevrier et al., 2004). This hypothesis is consistent with the recent Mössbauer observations of the soil performed by both MER landers, indicating substantial contents in paramagnetic $\mathrm{Fe}^{3+}$, characteristic of either nanocrystalline phases below their blocking volume (superparamagnetism), either of pure paramagnetic phase such as ferrihydrite or iron silicates (Klingelhöfer et al., 2004b, 2005; Morris et al., 2004). Alternatively, alteration in the past conditions may have rather favoured rapid conversion of ferrihydrite into crystalline phases, such as haematite and/or goethite. This recurrence of ferrihydrite as a precursor in many mechanisms of crystallisation, and in various alteration pathways makes it a probably important phase of the martian surface (Bishop et al., 2000).

\subsubsection{Magnetite $\left(\gamma-\mathrm{Fe}_{3} \mathrm{O}_{4}\right)$ and titanomagnetite $\left(\mathrm{Fe}_{3-x} \mathrm{Ti}_{x} \mathrm{O}_{4}\right)$}

These phases belong to the spinel group with a general formula of $\mathrm{M}_{3} \mathrm{O}_{4}$ where $\mathrm{M}$ is $\mathrm{Fe}, \mathrm{Ti}, \mathrm{Al}, \mathrm{Cr}$, or $\mathrm{Mg}$, etc. Titanomagnetite is generally the main carrier of natural magnetisation in primary rocks, but also in terrestrial soils (Mathé et al., 1999). This mineral is thought to be the main 
magnetic phase in the martian regolith (Hargraves et al., 1977; Hviid et al., 1997; Madsen et al., 2003, 1999). Mössbauer spectra obtained by MER Spirit on the surface of martian rocks (Adirondack rock) in Gusev Crater reveal a cation-deficient magnetite (Morris et al., 2004). Mössbauer spectra of the magnetic particles adhering to the magnets onboard MER rovers also show abundant magnetite (Goetz et al., 2005). Parameters of the spectrum indicate a small non-stoichiometric component resulting from the presence of titanium in the structure and/or oxidation of $\mathrm{Fe}^{2+}$ into $\mathrm{Fe}^{3+}$, suggesting titanomagnetite or titanomaghemite (oxidised titanomagnetite of general formula: $\quad \mathrm{Fe}_{[2-2 x+z(1+x)] R}^{3+} \mathrm{Fe}_{(1+x)(1-z) R}^{2+} \mathrm{Ti}^{4+}{ }_{x R} \square_{3(1-R)} \mathrm{O}_{4}$, with $R=8 /[8+z(1+x)], x$ being the rate of substitution in titanium, $z$ the rate of oxidation of the $\mathrm{Fe}^{2+}$ and $\square$ a gap in the structure of the titanomaghemite). Titanomaghemite often results from deuteritic and meteoritic alteration of titanomagnetite. Thus recent results seem to favor the presence of titanomagnetite more or less oxidized into titanomaghemite in martian soils in a similar way to Earth rocks and soils (Chevrier et al., 2006).

Titanomagnetite/titanomaghemite is generally thought to have been inherited from the parent rock through weathering processes (Coey et al., 1990; Gunnlaugsson et al., 2002; Hviid et al., 1997; Mathé et al., 1999). Experimental studies have confirmed the stability of magnetite even in highly oxidizing conditions (Chevrier et al., 2004). The martian basaltic subsurface rocks are probably rich in iron spinel-type oxides, as suggested by the abundance of spinel in the SNC meteorites. But in this case the magnetic properties of titanomagnetite are strongly dependent on the titanium content acquired at the time of the magma crystallization. The saturation magnetization decreases linearly with the rate of substitution (Hunt et al., 1995; Vlag et al., 1996). Some studies showed that the main carrier of natural magnetization in the shergottites is pyrrhotite $\mathrm{Fe}_{1-x} \mathrm{~S}$ (Rochette et al., 2001) rather than titanomagnetite. High contents in titanium do not allow titanomagnetite to account for the magnetic properties of the martian regolith (Hargraves et al., 2000; Madsen et al., 1995). Hargraves et al. (2000) propose that all the titanium of the martian regolith $(\sim 1 \%)$ results from the presence of about $4 \%$ of a titanomagnetite phase of Usp60 (Usp: ulvöspinel) or $x=$ 0.6 composition, typical of spinel found in terrestrial basalts and in SNCs, resulting in a regolith magnetization of $1.2 \mathrm{~A} \mathrm{~m}^{2} / \mathrm{kg}$, a value lower than the average measured magnetization, i.e. $4 \mathrm{~A} \mathrm{~m}^{2} / \mathrm{kg}$. However, this model ascribes the value of saturation magnetization to the global regolith, and does not take into account of a probable segregation of the magnetic phases by the magnets. Consequently, the limit obtained through the magnetic experiments is probably an upper boundary of saturation magnetization. The contribution of the titanomagnetite cannot therefore be refuted on this sole argument, especially when considering the new results of MER rovers.

\subsubsection{Maghemite $\left(\gamma-\mathrm{Fe}_{2} \mathrm{O}_{3}\right)$}

The second strongly magnetic phase thought to be present in the martian regolith is maghemite (Hargraves et al., 1979, 1977; Hviid et al., 1997; Madsen et al., 1999), that forms frequently in terrestrial weathering processes (Allan et al., 1988; Mathé et al., 1999). Unlike the titanomagnetites, maghemite is free of titanium, and therefore is always strongly magnetic. Furthermore, the spectroscopic data suggests the presence of maghemite in the regolith (Bell III et al., 2000; Morris et al., 2000), and in rock varnishes at the Pathfinder landing site (McSween et al., 1999). Maghemite appears also as a transitory phase when heating ferrihydrite/lepidocrocite (Barron and Torrent, 2002; Bishop et al., 2000; Morris et al., 1998) or nontronite (Moskowitz and Hargraves, 1984). Maghemite is a metastable phase in various weathering models. Consequently, its presence results from its low transformation rates, and is likely due to weathering in present day cold and dry martian climate (Chevrier et al., 2006). Finally the oxidizing and catalytic properties of the maghemite may explain some of the results of the biological experiments carried out by Viking (Oyama et al., 1978; Sherman et al., 1981).

\subsubsection{Lepidocrocite ( $\gamma$-FeOOH)}

Lepidocrocite has been proposed on the basis of some TES spectra acquired by Mars Pathfinder (Morris et al., 2000). Though relatively frequent on the Earth, the formation of lepidocrocite requires the oxidation of $\mathrm{Fe}^{2+}$ in solution, and consequently a relatively reducing environment, as well as a $\mathrm{pH}$ close to neutrality (Banin et al., 1993; Burns, 1993; Schwertmann, 1985). The formation of lepidocrocite and goethite is favoured by aqueous alteration on basaltic rocks (Posey-Dowty et al., 1986), while more acidic rocks favor haematite and goethite. Therefore, lepidocrocite and haematite are highly incompatible in the soil systems (Schwertmann, 1985). The presence of $\mathrm{CO}_{2}$ strongly favours goethite at the expense of lepidocrocite (Schwertmann, 1985). However, experimental weathering in primary martian conditions (high partial pressures of $\mathrm{H}_{2} \mathrm{O}$ and $\mathrm{CO}_{2}$ ) can produce lepidocrocite, associated to goethite, providing the conditions are sufficiently reducing. Some studies consider lepidocrocite a likely precursor to the formation of maghemite and haematite (Banin et al., 1993; Burns, 1993; Morris et al., 1998; Posey-Dowty et al., 1986), because the transformation of lepidocrocite into haematite, even if favoured thermodynamically, is not directly possible for crystallographic reasons and must proceed through maghemite (Cudennec and Lecerf, 2005). Consequently, though its presence in the martian regolith remains uncertain, lepidocrocite could appear as a minor phase associated to other iron (oxy)hydroxides.

\subsubsection{Akaganeite $\left(\beta-\mathrm{FeOOH}\right.$ or $\left.\beta-\mathrm{Fe}^{3+}(\mathrm{O}, \mathrm{OH}, \mathrm{Cl})\right)$}

As for lepidocrocite, akaganeite could describe some Mars Pathfinder spectra (Bell III et al., 2000; Morris et al., 2000) and a part of the nanophase paramagnetic (oxy)- 
hydroxide observed by Mössbauer spectrometry in Gusev Crater (Morris et al., 2006). However, there is a small possibility that akaganeite is present in substantial quantities in the martian regolith. Indeed akaganeite forms in environments highly enriched in chlorine (Schwertmann and Cornell, 1991), and data from the MER landers indicate $\mathrm{Cl}$ concentrations are below $1 \mathrm{wt} \%$ (Gellert et al., 2004; Rieder et al., 2004), even in Meridiani Planum that is of evaporitic origin, and therefore should be enriched in halides.

\subsubsection{Schwertmannite $\left(\mathrm{F}_{8}^{3+} \mathrm{O}_{8}(\mathrm{OH})_{6} \mathrm{SO}_{4}\right)$}

Schwertmannite is an iron oxyhydroxysulphate, structurally analogous to akaganeite. There is little data on its possible presence on the surface of Mars. Some works showed the possibility of complex analogues including schwertmannite and clays to describe some Earth-based measurements of thermal emission (Bishop et al., 1995), or Pathfinder TES spectra (Bishop et al., 1998b). On Earth, schwertmannite is frequently associated to jarosite $(\mathrm{K}, \mathrm{Na}, \mathrm{H}) \mathrm{Fe}_{3}\left(\mathrm{SO}_{4}\right)_{2}(\mathrm{OH})_{6}$ and goethite in acid mine drainage systems (Bigham et al., 1996; Regenspurg et al., 2004). The presence of this phase is possible considering the potential alteration pathways of martian subsurface rocks in acidic and sulphate-rich media (Burns, 1993, 1994; King and McSween, 2005). This hypothesis is reinforced by the recent discovery of jarosite in Meridiani Planum. The paramagnetic nanophase, associated to haematite and goethite, observed in Columbia Hills by the Mössbauer spectrometer on MER Spirit, could be described by schwertmannite, especially when considering the high sulphur abundance on Mars (Morris et al., 2006). Schwertmannite is also a metastable phase which transforms into goethite in relatively short timescale, of the order of years in experimental conditions (Bigham et al., 1996). Consequently, schwertmannite may also serve as precursor to other iron oxides and (oxy)hydroxides.

\subsubsection{Feroxyhyte ( $\delta$ - $\mathrm{FeOOH}$ or $\left.\delta^{\prime}-\mathrm{FeOOH}\right)$}

Feroxyhyte is probably the most "exotic" iron (oxy)hydroxide proposed for Mars. This mineral is indeed extremely rare at the surface of the Earth, due to extreme formation environments. The presence of feroxyhyte on Mars has been suggested on the basis of its red colour which is very similar to that of the martian surface (Burns, 1980a), its spectroscopic properties (Sherman et al., 1981), as well as its ferrimagnetism, suggesting that it is present as a strongly magnetic phase in the regolith (Burns, 1980a, 1993; Hviid et al., 1997). Finally, feroxyhyte has strong oxidising and catalytic properties that could explain the results of Viking biological experiments, and in particular the oxidation of the ${ }^{14} \mathrm{C}$ marked nutriments into $\mathrm{CO}_{2}$ (Burns, 1980a; Sherman et al., 1981). However, there are arguments against the presence of feroxyhyte on Mars. There are two polymorphs of feroxyhyte: the synthetic and strongly magnetic phase $\delta$ - $\mathrm{FeOOH}$, obtained by topotactic and rapid oxidation of $\mathrm{Fe}(\mathrm{OH})_{2}$ (Schwertmann and
Cornell, 1991) and the natural phase $\delta^{\prime}-\mathrm{FeOOH}$, which is weakly magnetic and forms by slow oxidation (Towe, 1980). It seems that the martian environment is inconsistent with the formation of strongly magnetic feroxyhyte. However, the presence of strong oxidants on Mars, suggested by Viking results (Oyama et al., 1978; Yen et al., 2000), and detected in the martian atmosphere (Clancy et al., 2004; Encrenaz et al., 2004), as well as the possibility of mixtures between $\delta$ and $\delta^{\prime}$ phases (Burns, 1980b) could allow feroxyhyte to coexist with other ferric oxides.

\subsection{Sulphur and sulphates}

Sulphur is a key element in understanding the evolution of the surface of Mars, due to the overall enrichment of the surface compared to the Earth. Indeed, high sulphur concentrations have frequently been detected in the soil by Viking: up to $10 \mathrm{wt} \% \mathrm{SO}_{3}$ (Baird et al., 1976; Clark et al., 1976; Toulmin III et al., 1976), by Pathfinder: up to $8 \mathrm{wt} \%$ $\mathrm{SO}_{3}$ (Bell III et al., 2000; Economou, 2001; Foley et al., 2003; Rieder et al., 1997), and finally by MER Spirit and Opportunity (Gellert et al., 2004, 2006; Rieder et al., 2004; Wang et al., 2006a). Thus high sulphur abundances are found over most of the known martian surface. The high sulphur concentrations are due to the presence of sulphates resulting from the alteration of basaltic bedrock. Specific bands of absorption of the mini-TES spectra achieved by MER Spirit and attributed to carbonates, could also result from the presence of hydrated iron sulphates: copiapite $\mathrm{Fe}^{2+} \mathrm{Fe}_{4}^{3+}\left(\mathrm{SO}_{4}\right)_{6}(\mathrm{OH})_{2} \cdot 20 \mathrm{H}_{2} \mathrm{O}$, rozenite $\mathrm{FeSO}_{4} \cdot 4 \mathrm{H}_{2} \mathrm{O}$ or szomolnokite $\mathrm{FeSO}_{4} \cdot \mathrm{H}_{2} \mathrm{O}$ (Lane et al., 2004). In addition to the sulphates present in the soil, sulphates have been identified in sedimentary outcrops of Meridiani Planum by the Mössbauer and mini-TES spectra onboard MER Opportunity, which detected concentrations of up to $25 \mathrm{wt} \% \mathrm{SO}_{3}$ (Rieder et al., 2004; Squyres et al., 2004b). The main sulphates identified are jarosite $(\mathrm{K}, \mathrm{Na}, \mathrm{H}) \mathrm{Fe}_{3}$ $\left(\mathrm{SO}_{4}\right)_{2}(\mathrm{OH})_{6}$ (Klingelhöfer et al., 2004b), gypsum $\mathrm{CaSO}_{4} \cdot 2 \mathrm{H}_{2} \mathrm{O}$ and magnesium suflates (Clark et al., 2005; Squyres et al., 2004b; Wang et al., 2006a). $\mathrm{Mg}, \mathrm{Fe}^{3+}$ and Ca-sulphates have also been identified by MER Spirit in Columbia Hills outcrops, with contents as high as about $40 \%$ in Paso Robles (Ming et al., 2006).

Apart from the localised observations carried out by the various landers, the orbiter Mars Express OMEGA has also performed some observations and mapping of sulphates deposits on the surface of Mars (Fig. 7, Bibring et al., 2005). Various sulphates have then been identified, including gypsum (Langevin et al., 2005), kieserite $\mathrm{MgSO}_{4} \cdot \mathrm{H}_{2} \mathrm{O}$ and polyhydrated sulphates (Gendrin et al., 2005). The layered terrains containing the sulphates represent important deposits, tens of $\mathrm{km}$ wide, and with a thickness of a few km (Bibring et al., 2005; Gendrin et al., 2005). There are various hypotheses for the formation of these deposits: from evaporitic deposition in water bodies (Gendrin et al., 2005), following the scheme developed for 


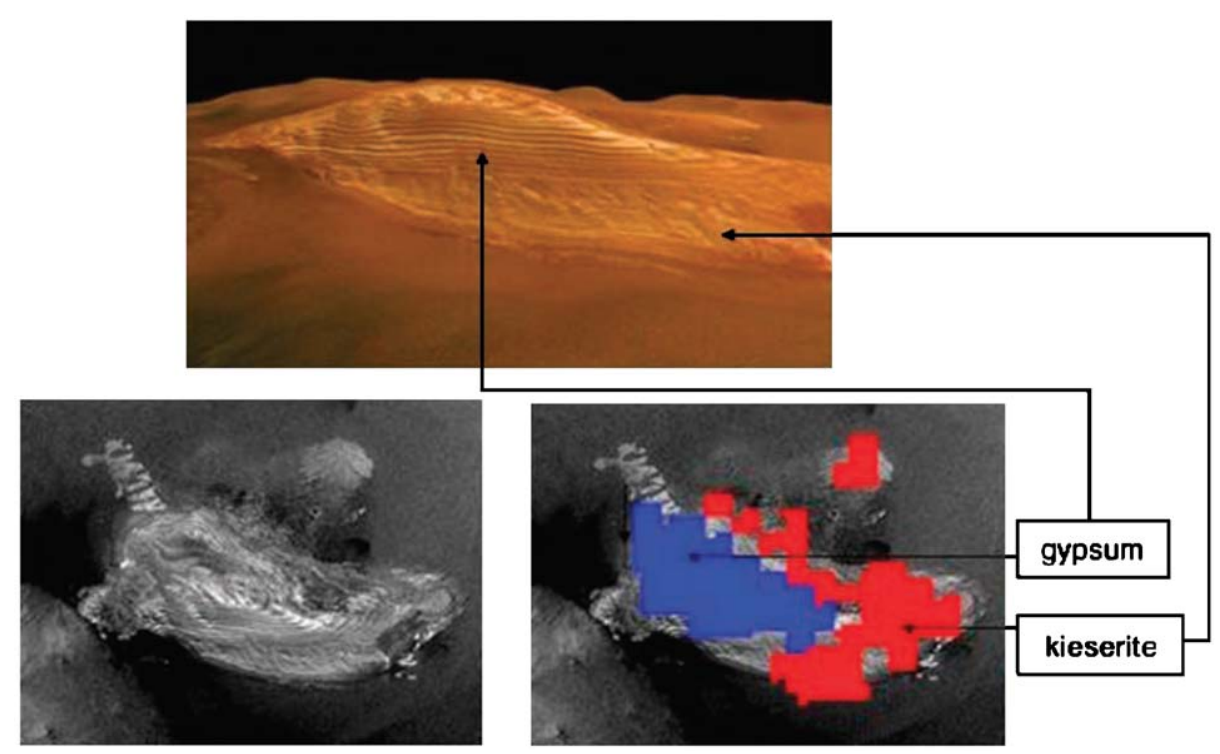

Fig. 7. 2.5-km-high and 40-km-long sulphate-rich layer deposit in Juventae Chasma, Valles Marineris. The top image corresponds to the threedimensional picture taken by the HRSC-Mars Express Camera. Bottom images correspond to the MOC-MGS picture (left) and superimposed mineralogical mapping (right), revealing sulphates gypsum (blue) and kieserite (red). Source of the image: Bibring et al. (2005).

martian evaporites (Catling, 1999) to in situ weathering of sulphides deposits or basaltic materials (ashes) in the presence of waters enriched in sulphuric acid (Bibring et al., 2005), following the hypothesis of Burns (1993). The presence of high abundances of gypsum in a large deposit near the north polar cap (Langevin et al., 2005) poses the problem of the source material, i.e. enriched in $\mathrm{Ca}$, whereas the overall surface of Mars is generally enriched in $\mathrm{Fe}$ and $\mathrm{Mg}$.

Two scenarios explain the presence of such high abundances of sulphate on the martian surface: alteration of sulphide-rich rocks and alteration in the presence of $\mathrm{SO}_{2}$ (acid fog or groundwater). All iron sulphates (jarosite) have long been known in the mining environments where they form from the weathering of sulphide deposits (Sracek et al., 2004). In addition, models of martian surface weathering supposed the formation of sulphates from alteration of large deposits of sulphides (pyrrhotite) usually associated to the komatiitic formations on Earth (Burns and Fisher, 1990b,c, 1993) or eventually from pyrite resulting from hydrothermalism (Zolotov and Shock, 2005). The presence of such amounts of sulphides may result from an important enrichment of the martian lithosphere in sulphur, linked to the differentiation and accretion of Mars (Clark and Baird, 1979). The alteration of sulphides generates acidic waters $\left(\mathrm{H}_{2} \mathrm{SO}_{4}\right)$, favouring the dissolution of the surrounding silicates. The other source of sulphur on the martian surface is the $\mathrm{SO}_{2}$ degassed by volcanoes (Postawko, 1985; Wänke et al., 1992). This $\mathrm{SO}_{2}$ can further be converted into $\mathrm{H}_{2} \mathrm{SO}_{4}$ in presence of water, forming an acid fog, that can very efficiently alter the basaltic subsurface rocks, inducing the crystallisation of sulphates (Banin et al., 1997; Hurowitz et al., 2006; Moore and Bullock, 1999; Tosca et al., 2004). Given that volcanism remained efficient until a relatively recent period (Hartmann et al., 1999), this type of alteration mechanism could have been periodically active on a long timescale (Banin et al., 1997). In this case, the observed regolith may be the result of a recent process and covers the earlierformed regolith (Banin, 1996; Banin et al., 1997). Banin et al. (1997) has also suggested a possible difference in the nature of the recently formed sulphates and the older sulphates, which is that early processes involved precipitation of insoluble sulphates (jarosite), while recent weathering processes under anhydrous conditions favours the formation of more soluble sulphates (kieserite, alunogen etc.). Sulphates usually contain structural water which could constitute a reservoir of surficial water. Depending on the water partial pressure, changes in the nature of the phase (gain or loss of water molecules) could induce variations in space (latitude, altitude) and time of the observed sulphates (Vaniman et al., 2004).

\subsection{Carbonates}

Many studies have predicted a primitive martian atmosphere enriched in $\mathrm{CO}_{2}$ and $\mathrm{H}_{2} \mathrm{O}$, with pressures of one to several bars (Forget and Pierrehumbert, 1997; Nakamura and Tajika, 2001; Pollack et al., 1987). Therefore, carbonates are very important phases to constrain the evolution of the Mars surface, as they represent the main witnesses of the primitive interaction between the atmosphere, the hydrosphere and the lithosphere. This hypothesis is founded on the intense volcanic activity, as observed for the Tharsis dome, and that has certainly involved (or released) huge quantities of gas in the atmosphere (Phillips et al., 2001). This dense cloudy covering would have induced an intense greenhouse effect (Forget and 
Pierrehumbert, 1997), enabling liquid water to exist on the surface for long times. On Earth, the interaction between the primitive $\mathrm{CO}_{2}$-rich atmosphere/hydrosphere, and the basaltic subsurface rocks enriched in iron induced the formation of siderite $\mathrm{FeCO}_{3}$ (Ohmoto et al., 2004). By analogy, and on the basis of the higher Fe concentration in the martian surface, many authors assume that large amounts of carbonates/siderite should have precipitated in primitive martian conditions (Catling, 1999; Fairen et al., 2004; Kahn, 1985; King et al., 2004; Marion et al., 2003), trapping the $\mathrm{CO}_{2}$ and cooling the climate (Morse and Marion, 1999). Moreover, thermodynamic studies show that in the absence of oxygen, siderite is stable in the present day conditions of Mars (Booth and Kieffer, 1978; Gooding, 1978). Finally, mass balance studies suggest that a deficiency in calcium of the martian regolith compared to the SNC's indicates an important leaching of $\mathrm{Ca}$, and thus a carbonate reservoir (Warren, 1987).

It would therefore be logical to expect relatively high carbonate contents in the martian surface. However, carbonates constitute only a trace in the surface today. Some hydrated carbonates of magnesium, such as hydromagnesite $\mathrm{Mg}_{5}\left(\mathrm{CO}_{3}\right)_{4}(\mathrm{OH})_{2} \cdot 4 \mathrm{H}_{2} \mathrm{O}$ or artinite $\mathrm{Mg}_{2}\left(\mathrm{CO}_{3}\right)_{3}(\mathrm{OH})_{2} \cdot 3 \mathrm{H}_{2} \mathrm{O}$, have been suggested on the basis of the infrared spectra produced by Mariner 6 and 7 (Calvin et al., 1994), while carbonate contents bellow 5\%, scattered in the soil, have been detected in the MGS-TES spectra (Bandfield et al., 2003). MER Spirit seems also to have detected traces of carbonates $(<5 \%)$ in the regolith of Gusev Crater (Christensen et al., 2004a), though the spectral features are also attributable to some iron sulphates (Lane et al., 2004). Finally the best identification of carbonates on Mars remains the discovery of complex concretions of $\mathrm{Ca}-\mathrm{Mg}-\mathrm{Fe}$ carbonates in the martian meteorite ALH84001 (Mittlefehldt, 1994). The formation of these carbonates has been highly debated. Interactions with the atmosphere (Farquhar et al., 1998), with lowtemperature aqueous solutions (Kirschvink et al., 1997; Romaneck et al., 1994; Valley et al., 1997), or hydrothermal processes (Treiman et al., 2002) have been discussed. Siderite has also been identified in other altered SNC's and has been linked to evaporitic paragenesis (Bridges et al., 2001).

There are various hypotheses to explain the lack of abundant carbonates on Mars. In the case of an evaporitic sequence, carbonates are the first phases to precipitate because of their very low solubility. The carbonates could therefore be hidden by other more soluble salts crystallising above, such as sulphates or halides (Catling, 1999). The study of the Opportunity site may help to resolve the crystallisation sequence of the martian evaporites. Carbonates can also form alteration varnishes of micrometer thickness on the surface of basaltic grains altered in presence of an $\mathrm{H}_{2} \mathrm{O}$-poor atmosphere (Booth and Kieffer, 1978). These authors show that an important part of the primitive $\mathrm{CO}_{2}$ could be present as this form. Supposing a regolith of $1 \mathrm{~km}$ thickness, the concentration in carbonates would not exceed $0.1 \mathrm{wt} \%$, a value clearly below the detection limits of nearly all the spectrometers. This hypothesis has the advantage of not requiring abundant liquid water, or a primitive thick atmosphere. Alteration is in this case a continuous phenomenon with very long timescales, of the order of $1 \mathrm{Ga}$. Such a mechanism describes efficiently the traces of carbonates observed in the martian soil (Bandfield et al., 2003), and corresponds to the formation of carbonates in the present day conditions $\left(\mathrm{CO}_{2}\right.$ and low $\mathrm{H}_{2} \mathrm{O}$ partial pressure). Alternatively, a primary $\mathrm{CO}_{2}$ and $\mathrm{H}_{2} \mathrm{O}$-rich atmosphere should rather lead to consequent layers of carbonates, in a similar way as carbonate formation on the Earth. Finally, it is also possible that the formation of very acid solutions due to the volcanic $\mathrm{SO}_{2}$ or to the alteration of sulphides may have dissolved pre-existing carbonates and/or prevent their crystallisation (Fairen et al., 2004; Moore, 2004), an hypothesis based on the incompatibility between sulphates and carbonates formation conditions (Fig. 8). This phenomena may have been also reinforced by the dynamic escape of $\mathrm{CO}_{2}$ into space (Bibring et al., 2005). In addition, acid leaching could have dragged the carbonates deep in the regolith, releasing them only in the deep permafrost.

\section{Alteration on Mars}

\subsection{The primary rocks}

On the Earth, at a global scale soil formation depends on latitude (i.e. insulation, humidity), but at a local scale, the nature of the primary rock is a predominant factor that governs soil formation at the local scale, that is to say, for a given insolation and humidity (Pédro, 1964). The primary martian rocks are essentially basaltic to andesitic. Many studies emphasise the importance of the primary mineralogy in addition to the physico-chemical conditions of the alteration processes (Griffith and Shock, 1997; Hurowitz et al., 2005; Tosca et al., 2005). Studies of the SNC shows that they are enriched in oxides and sulphides (Lorand et al., 2005) which could account in part for the resulting properties of the regolith. However, there is a second source of reduced material on the surface of Mars, provided by the meteoritic contributions. Indeed, contrary to the Earth, the absence of plate tectonics prevents martian surface recycling. Consequently, meteoritic material accumulates on the surface, where it can be altered and mixed with the basaltic component (Newsom and Hagerty, 1997). Some models estimate a meteoritic input up to $30 \%$ of the mass of the regolith (Bland and Smith, 2000; Flynn and McKay, 1990). The average mineralogy of the meteoritic material is relatively different from basaltic rocks. In addition to a more important concentration in sulphides, especially in troilite $\mathrm{FeS}$, exogenic material also contains iron-nickel metallic alloys (kamacite and taenite). These alloys, in addition to their very strongly magnetic character (Gattacceca et al., 2003) provide an additional source of iron in the soil (Chevrier et al., 2004). MER Spirit 

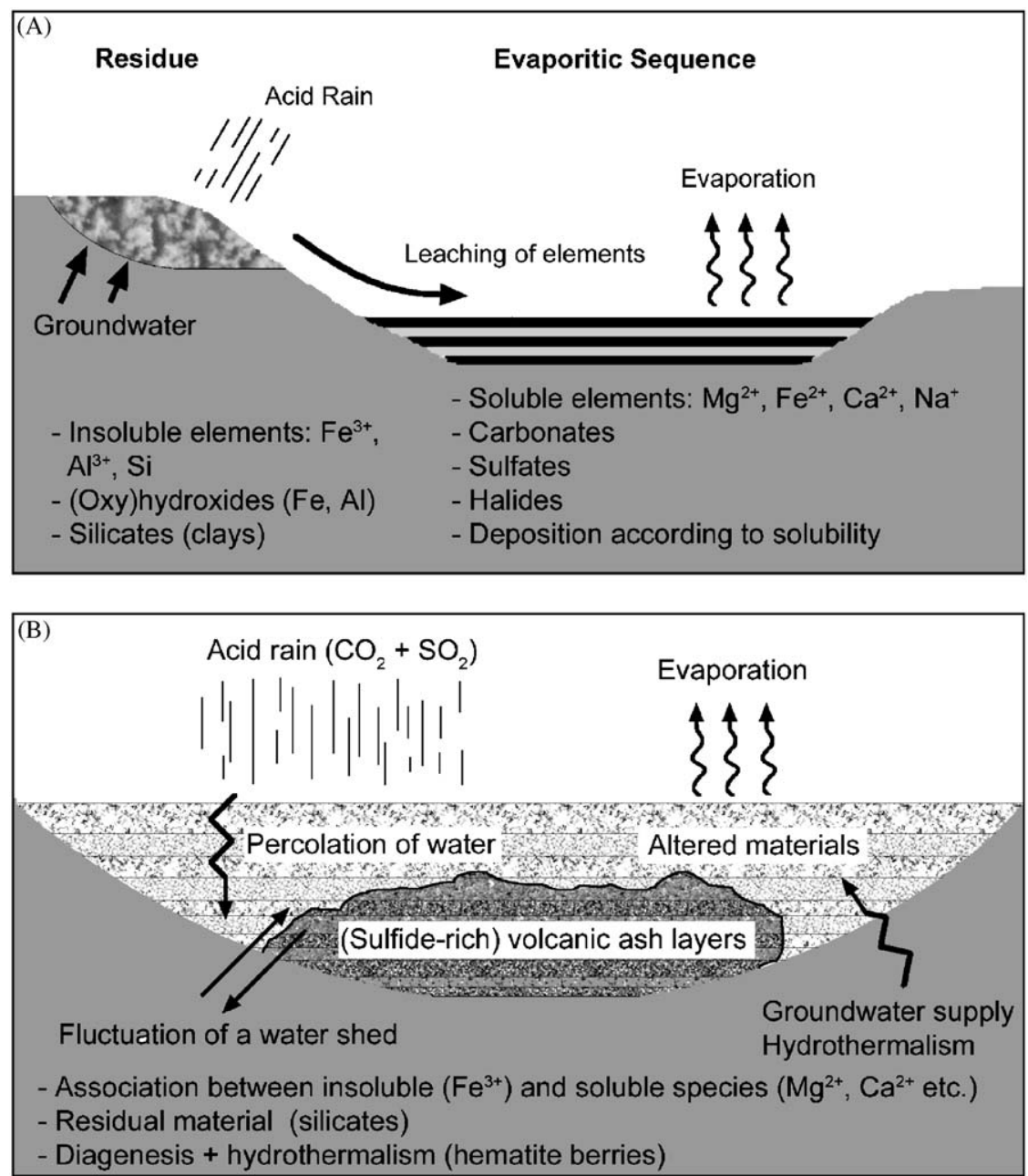

Fig. 8. Schemes of the two possible processes for the formation of Meridiani Planum, and other sulphate deposits on Mars: (A): Hypothesis of alteration, leaching, transport and subsequent deposition in a lake or a sea. (B): Hypothesis for in situ alteration and transformation of minerals, driven by the input and evaporation of water.

has shown that nickel contents increase from the fresh rocks, to their altered surface, and then to the regolith (Gellert et al., 2004). These observations show a probable an enrichment of the martian regolith of about $1 \%$ in meteoritic matter (Gellert et al., 2006; Yen et al., 2005).

\subsection{Palagonitisation, evaporites and low-temperature aqueous alteration}

Palagonitisation is defined by the alteration of volcanic glass by liquid water, usually in a sea or a lake (Noack, 1981). Therefore, palagonites are very appropriate objects to study the aqueous alteration of the martian surface. Terrestrial palagonites often present great spectral and mineralogical resemblances with the martian soil, and especially by the association of more or less crystalline ferric oxides and (oxy)hydroxides: haematite, goethite and ferrihydrite, with magnetic oxides of spinel type inherited from parent rock (Bell III et al., 1993). The presence of phyllosilicates in the secondary paragenesis of these palagonites also makes these objects very good analogues of the martian soil in term of mineralogical and chemical properties (Bishop and Pieters, 1995). However, the term palagonitisation/palagonite is often related to weathering or aqueous alteration of volcanic ashes. Given the geomorphological evidence of water activity on Mars, at least until $3 \mathrm{Ga}$, alteration by liquid water has probably been highly active. Experimental work show that basaltic material has been altered by surface/subsurface water in equilibrium with the atmosphere rather than by deep seawater (Bullock et al., 2004) supporting the weathering hypothesis. It seems however that water activity and weathering are linked to evaporitic processes. The studies on the mineralogy of SNC meteorites have also evidenced complex evaporitic parageneses: sulphates, carbonates and halides (Bridges et al., 2001; Bridges and Grady, 2000; Gillet et al., 2002; Gooding et al., 1991; Treiman et al., 1993; Wentworth and Gooding, 1994). This type of paragenesis fits well the models of evaporite deposits where the nature of the secondary phases evoloves according to their solubility (Catling, 1999). Furthermore, the study of the soils at the Viking and Pathfinder sites shows a 
systematic mixing between a primary pole, basaltic or andesitic, and an evaporitic pole with sulphates and halides (Larsen et al., 2000).

Meridiani Planum formations are believed to result from acid-alteration, evaporitic and diagenetic process in a shallow sea (Squyres et al., 2004a, b; Squyres and Knoll, 2005) even if other scenarios like weathering of impact related sedimentary layers remain plausible (Knauth et al., 2005). The textures of the outcrops indicate a subaqueous deposit with stratified sedimentary deposits presenting figures of cross-bedding resulting from the fluctuation of a table water (Grotzinger et al., 2005; Herkenhoff et al., 2004; Squyres et al., 2004b). The presence of abundant sulphates, as well as elements such as $\mathrm{Cl}$ or $\mathrm{Br}$ (Rieder et al., 2004), suggests a deposit in evaporitic environment, from progressively saturated solutions. Although evaporites observed in Meridiani Planum, and probably other sulphate-type deposits observed by Mars Express OMEGA, rely on water activity, it seems that this activity remained limited in space and time (Squyres and Knoll, 2005). This limited activity is supported by large variations of $\mathrm{Cl}$ and $\mathrm{Br}$ contents of the sediments, indicating rapid changes in $\mathrm{pH}$ and water content (Clark et al., 2005). Usual evaporites on Earth are mainly composed of soluble salts deposited according to their solubility. These salts are the most soluble species, leached from primary rocks and transported by rivers into a sea or a lake (Fig. 8A). However, Meridiani outcrops seem to contain about $40 \%$ Si (Rieder et al., 2004; Squyres et al., 2004b), or 20-25 wt \% amorphous silica (Clark et al., 2005). This is not compatible with a pure evaporitic deposit, given the low solubility of silica. The presence of high iron concentrations (haematite) also indicates in situ weathering and evaporation rather than a leaching, transfer, and subsequent deposition. Indeed, iron is usually considered as an "immobile" element, due to its very low solubility in oxidative conditions (Brimhall and Dietrich, 1987; Eggleton et al., 1987). If considering pure evaporites formed from high water-to-rock ratio, large volumes of primary rocks must have been weathered to release soluble ions, implying that large volume of residues, usually enriched in "immobile elements" such as $\mathrm{Fe}, \mathrm{Al}, \mathrm{Ti}, \mathrm{Zr}$ and corresponding mineralogies (iron (oxy)hydroxides, aluminium (oxy)hydroxides, etc.) should be observed. Alternatively, low water-to-rock ratios and rapid evaporation induce high salt-to-water ratios (King et al., 2004), allowing precipitation of incompatible phases, i.e. residual amorphous silica with insoluble jarosite and highly soluble Mg-sulphates/kieserite and Fe-sulphates (Tosca et al., 2005). This suggests that waters reacted directly in situ with layers and became strongly enriched in soluble elements, instead of being transferred in lakes/seas through leaching (Fig. 8B, King and McSween, 2005). The presence of jarosite in Meridiani Planum outcrops testifies of very specific conditions, as this mineral precipitates at $\mathrm{pH}$ around 2-3 (Fig. 9, Papike et al., 2006). This indicates alteration by very acidic water that has not acted for a

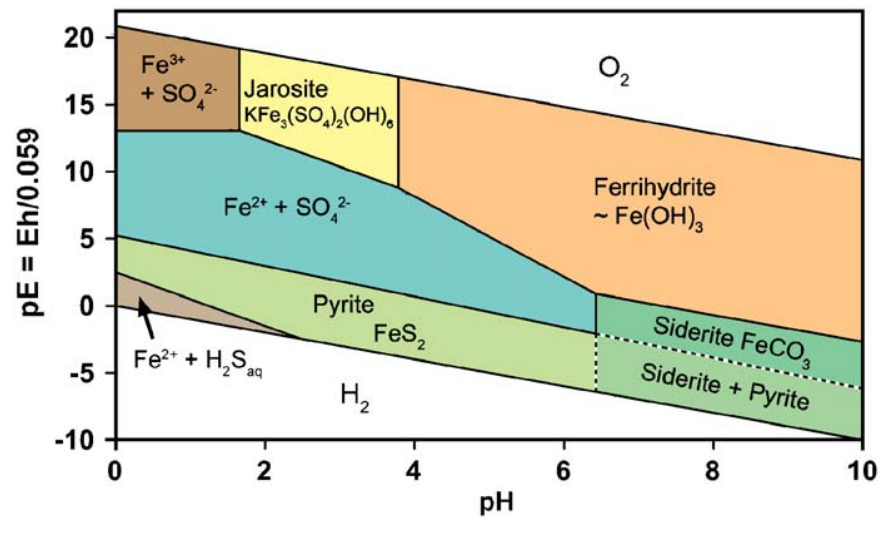

Fig. 9. Phase diagram of iron phases, including siderite and jarosite at pressure of $1 \mathrm{~atm}$ (considered here as $100 \% \mathrm{CO}_{2}$ ), and temperature of $298.15 \mathrm{~K}$. Activities of dissolved species $\left(\mathrm{SO}_{4}^{2-}: 1.8 \times 10^{-4} \mathrm{~mol} / \mathrm{L}, \mathrm{K}^{+}\right.$: $7 \times 10^{-5} \mathrm{~mol} / \mathrm{L}, \mathrm{Fe}^{2+}: 8 \times 10^{-4} \mathrm{~mol} / \mathrm{L}$ ) are taken from Catling (1999), thermodynamic data for jarosite, $\mathrm{SO}^{2-}$ and $\mathrm{K}^{+}$: Baron and Palmer (1996), for pyrite: Benning et al. (2000), others values: CRC Handbook of Chemistry and Physics, 76th Edition, D.R. Lide Editor in Chief.

sufficient time to reequilibrate with the surrounding material (King and McSween, 2005; Madden et al., 2004; Tosca et al., 2005). Such very acid conditions allow solubilisation of $\mathrm{Al}$ and $\mathrm{Fe}$, which limit also the fractionation between soluble elements in evaporitic parageneses and unsoluble elements in residual assemblages (Hurowitz et al., 2006). In this case, the secondary mineralogy is controlled by the composition of the primary rock (Tosca and McLennan, 2006; Tosca et al., 2005). This can be achieved by percolation and/or fluctuation of a water table inside a basaltic layer (ashes), accompanied by evaporation which has been active in this system (Tosca et al., 2005), and even necessary as the main process preventing equilibration of water.

Models show that $\mathrm{Fe}^{2+}$-sulphates (melanterite $\mathrm{FeSO}_{4} \cdot 7 \mathrm{H}_{2} \mathrm{O}$ ) could result from first step of alteration (King and McSween, 2005; Tosca et al., 2005). Further evolution of these sulphates in oxidising conditions may have formed the $\mathrm{Fe}^{3+}$-sulphates such as jarosite and copiapite. Then changes of $\mathrm{pH}$ may have induced destabilisation of sulphates into iron (oxy)hydroxides, i.e. ferrihydrite, schwertmannite and goethite (Burns, 1988; Burns and Fisher, 1990c; Chevrier et al., 2004; FernandezRemolar et al., 2005; King and McSween, 2005). Thus, in that sense Meridiani Planum may be the result of a palagonitisation weathering mechanism, and testifies of intermittent water activity on the surface of Mars probably during billions of years (Glotch and Christensen, 2005). In the same way sulphate deposits observed by Mars Express OMEGA, and often associated to iron (oxy)hydroxides (Bibring et al., 2005) may result from the same kind of process, when water became scarce, and was then acidified by gases in periods of sporadic volcanic activity (Poulet et al., 2005), inducing in situ (i.e. without leaching and transfer of ions) weathering of preexisting rocks/ashes layers. Geomorphologically, most 
of the sulphate deposits correspond to mountains or walls of canyons like in Valles Marineris (Gendrin et al., 2005). In the leaching model, this implies deposition in a basin and then a further huge erosion of these deposits, in an alternate unknown reservoir, even if aeolian erosion and subsequent mixing in the soil may account for the "missing" sulphates.

Apart from Meridiani Planum, the rover Spirit has also evidenced water activity in Gusev Crater, mainly in the Columbia Hills, where impact ejecta have undergone different steps of aqueous alteration (Squyres et al., 2006), leading to various alteration parageneses. These parageneses include sulphates, iron (oxy)hydroxides (goethite, haematite), phosphates, etc., all present in rocks having undergone slight to extensive weathering (Ming et al., 2006). However, even if the acid fog model remains favoured (Hurowitz et al., 2006), the extreme variability in mineralogy, geochemistry, and alteration state (Ming et al., 2006) argues for a limited action of water in this region. Even the presence of sulphates in the soil indicate limited action of water, through small-scale ion transport and evaporation processes (Wang et al., 2006a). The presence of clays indicates also possible weakly acidic conditions (Wang et al., 2006b). This indicates that the weathering on Mars can present an important variability at a very local scale (Ming et al., 2006), which may complicate deciphering the precise conditions and processes at the origin of the formations.

\subsection{Hydrothermal processes and thermal activity}

Hydrothermal processes correspond to alteration of host rock by high-temperature aqueous fluids $\left(>100{ }^{\circ} \mathrm{C}\right)$, generally induced by volcanic activity. The main indicators of hydrothermal activity come from the study of the martian SNC meteorites. Indeed many SNCs present alteration assemblages (Bridges et al., 2001), as well as isotopic signatures typical of hydrothermal processes (Greenwood et al., 2000). In addition, there is a certain mineralogical similarity between Mars and terrestrial hydrothermal systems: (oxy)hydroxides and clays (Wade et al., 1999). The enrichment in volatiles (sulphur, chlorine and bromine) of the martian soil is also a good argument for an hydrothermal contribution (Newsom and Hagerty, 1997; Newsom et al., 1999), or volcanic exhalations (Banin et al., 1997). Finally, hydrothermal processes could be an efficient mechanism to store water in the crust, under the form of hydrated secondary phases (Griffith and Shock, 1997). However, hydrothermal processes lead to phase assemblages quite different from those found in the martian regolith (Baker et al., 2000; Hurowitz et al., 2005), and do not describe the abundance of iron oxides and (oxy)hydroxides compared to other phases (Newsom et al., 1999). Nevertheless, hydrothermal activity contribution must be considered as a source for specific phases, particularly in the case of subsequent aeolian rehomogeneisation.
Studies of the alteration assemblages in the SNCs show that they result from low-temperature hydrothermal processes and are heterogeneously distributed (Baker et al., 2000; Borg and Drake, 2005; Greenwood et al., 2000). Hydrothermal processes are rather linked to local circulations of fluids at the end of the lava cooling, and eventually to interactions with the martian atmosphere (Farquhar et al., 2000; Farquhar and Thiemens, 2000). Nevertheless, hydrothermal processes during burial diagenesis in Meridiani Planum outcrops could have modified the mineralogy and structure of preexisting deposits (Glotch and Christensen, 2005). Circulation of hightemperature fluids may have allowed dissolution of iron precursors and subsequent reprecipitation of haematite berries (Chan et al., 2004; Morris et al., 2005), dissolving also some highly soluble phase, creating the porosity evidenced in the rocks (McLennan et al., 2005). Jarosite is usually in equilibrium with goethite/ferrihydrite, rather than haematite (Arslan and Arslan, 2003; Burns and Fisher, 1990c; Catling, 2004; Chevrier et al., 2004). Similarly, goethite conversion from ferrihydrite is promoted at low $\mathrm{pH}$ and low temperature, whereas higher temperatures and $\mathrm{pH}$ induce haematite formation (Fig. 10, Schwertmann et al., 1999). Thus nearly all (oxy)hydroxides can be easily converted into haematite if the temperature increases (Schwertmann and Cornell, 1991; Schwertmann et al., 1999). On the basis of the mineralogical analogy with the Rio Tinto river, some authors proposed a mechanism of diagenetical dehydratation and desulphatation to form haematite from $\mathrm{Fe}^{3+}$-sulphates and goethite paragenesis (Fernandez-Remolar et al., 2004, 2005, 2003).

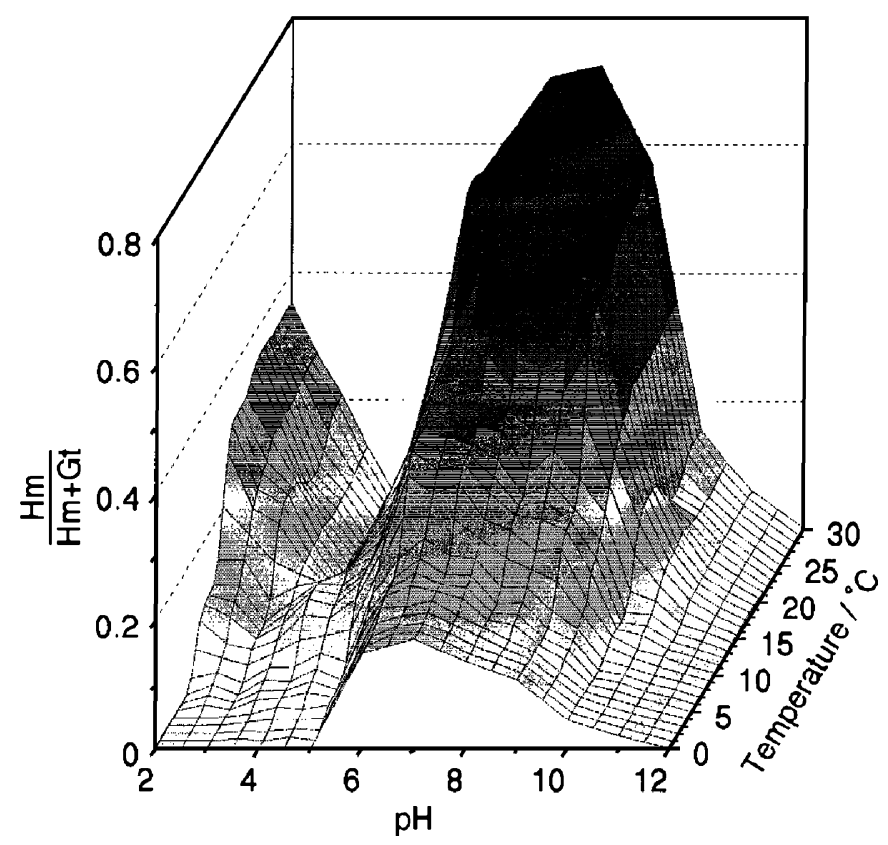

Fig. 10. Haematite (Hm) and goethite (Gt) formation from ferrihydrite$2 \mathrm{~L}$ in the $\mathrm{pH}$ range of $2-12$ and the temperature range of $4-30{ }^{\circ} \mathrm{C}$ after 9.3-12.6 years of storage in water. The graph is interpolated from data obtained at $\mathrm{pH} 2.5-12$ in one-unit steps and at $4,10,15$, and $25^{\circ} \mathrm{C}$. Source of the graph: Schwertmann et al. (1999). 


\subsection{Effect of the atmosphere}

The nature of the atmosphere in which weathering develops has an influence on the nature of the secondary phases. Indeed, not only the atmosphere can directly affect the primary substratum, but it also controls the composition of the hydrosphere. The chemical compositions of the atmospheres of the Earth and Mars are indeed very different. The fundamental differences are the content in $\mathrm{CO}_{2}: 95 \%$ of the martian atmosphere against $0.03 \%$ for the Earth, and especially the content in oxygen: $21 \%$ for the Earth against $0.1 \%$ for Mars. Such differences induce variations in $\mathrm{pH} / \mathrm{eH}$ of the solutions, in equilibrium with the atmosphere. Thus $\mathrm{CO}_{2} / \mathrm{SO}_{2}$-rich atmospheres are equilibrated with more acid solutions, while the content in $\mathrm{H}_{2} / \mathrm{O}_{2}$ will control the oxydoreductant character of the solutions. Thermal escape of $\mathrm{H}_{2}$ is probably the main process responsible for the irreversible oxidation of the surface of Mars, through alteration reactions either involving acidic waters and $\mathrm{H}^{+}$(Chevrier et al., 2004), either $\mathrm{O}_{2}$ produced by photodissociation of $\mathrm{H}_{2} \mathrm{O}$ (Lammer et al., 2003, 1996) either oxidation of water by $\mathrm{CO}$ produced by photodissociation of $\mathrm{CO}_{2}$ (Hodges, 2002). $\mathrm{H}_{2}$ escape has already been suggested to explain the oxidation and $\mathrm{O}_{2}$ rising of Early Earth (Catling et al., 2001). Thus weathering on Mars has probably first occurred through $\mathrm{Fe}^{2+}$ chemistry (High $\mathrm{H}_{2} /$ low $\mathrm{O}_{2}$ ) and further evolved through $\mathrm{Fe}^{3+}$ chemistry (low $\mathrm{H}_{2} /$ high $\mathrm{O}_{2}$ ), as described by various models of evolution of chemical conditions on Mars (King and McSween, 2005; Marion et al., 2003).

Another important type of erosion of the atmosphere is due to the solar wind ("sputtering") and affects for example $\mathrm{CO}_{2}$ (Johnson and Liu, 1998; Leblanc et al., 2002). $\mathrm{CO}_{2}$ sputtering from Mars may be the driving force for the absence of carbonates from Mars. In this model, carbonates have been destabilised by acid conditions on early Mars (Fairen et al., 2004), and the loss of $\mathrm{CO}_{2}$ from Mars would have prevented any reprecipitation, leading to the carbonate depleted surface (Bibring et al., 2005). However, the presence of clays in the south crust (Poulet et al., 2005) suggests that conditions were more weakly acidic during the Noachian. So if they ever formed, carbonates may be present in these regions, although they have not been still detected (Bibring et al., 2005).

Since the Viking experiments, many hypotheses have been proposed for the presence of a strong oxidising agent in the martian soil, and its probable atmospheric origin (Oyama et al., 1978; Yen et al., 2000). Recently, the detection of $\mathrm{H}_{2} \mathrm{O}_{2}$ in the martian atmosphere (Clancy et al., 2004; Encrenaz et al., 2004) reinforced this hypothesis. The martian atmosphere evidences a complex photochemistry, resulting from the intense UV radiation (Patel et al., 2002), and producing strongly oxidising species that react with the regolith (Oyama and Berdahl, 1979). UV radiation is also responsible for the lost of some elements through various mechanisms, but which may have strong consequences on the evolution of the surface of Mars.

\subsection{Weathering in present day conditions}

On Earth many red soils formed on basaltic parent rock, in tropical climate, have analogous properties to the martian soils (Fig. 11). These soils show almost systematically the association of coloured iron (oxy)hydroxides, essentially haematite and goethite, and strongly magnetic spinel, either titanomagnetite inherited from the primary rock, either secondary maghemite (Allan et al., 1988; Goulart et al., 1998; Mathé et al., 1999; Resende et al., 1986). Thus the Earth and Mars may have undergo similar regolith formation processes (Burns, 1993), but in conditions clearly different. In present day conditions, haematite is the stable iron oxide (Gooding, 1978). However, the recent discovery for goethite (Fig. 6, Klingelhöfer et al., 2005; Morris et al., 2006), associated to haematite and a paramagnetic phase, indicates that this mineral is present at least in a metastable state on Mars. Experimental studies indicate that in the presence of abundant water, goethite forms rather than haematite (Burns and Fisher, 1990c; Chevrier et al., 2004). But if water is weak or even absent, reducing ion mobility, ferrihydrite can perpetuate (Schwertmann et al., 1999). Fig. 12 shows the thermodynamic equilibriums for the reactions involving ferrihydrite, goethite and haematite. In the whole range of temperature and water activity of the martian surface, ferrihydrite should destabilise into goethite/haematite. There is yet a region in the $\left(a_{\mathrm{H}_{2} \mathrm{O}}, T\right)$ space where goethite is stable, i.e. at low temperature. Therefore, goethite should be stable at high latitudes, where also all climate models and spacecraft observations indicate high water abundance (Feldman et al., 2004). Nevertheless, both goethite and ferrihydrite can be present in regions of unstability, because the modelled reactions occur with gaseous water, and are then subjected to be extremely slow (Gooding, 1978). Such mechanisms could explain the abundance in the soil and fine dust fraction of paramagnetic ferric phases (Klingelhöfer et al., 2004b; Morris et al., 2004), typical of poorly evolved nanophases, which in turn could account for the hiding of the northern plains in OMEGA signal (Mustard et al., 2005) as well as the TES surface type II.

Possible weathering of primary minerals in martian conditions has been studied through two main mechanisms: either by liquid-solid interaction (Burns, 1993; Burns and Fisher, 1990c; Catling, 1999), or by solid-gas mechanism (Gooding, 1978). The first mechanism is the more usual and the main responsible for soil formation on the Earth. Schematically, it occurs through condensation, precipitation and circulation of water, like in the lateritic profiles developed in tropical climate (Nahon, 1991; Tardy et al., 1988a, b; Tardy and Nahon, 1985). Such weathering process can also act through frost-thaw, like in weathering profiles developed in polar or Antarctic climate (Bender Koch et al., 1995; Chevrier et al., 2006; Dickinson and Rosen, 2003). On Mars, weathering by films of liquid water seems to be indicated by soluble elements 


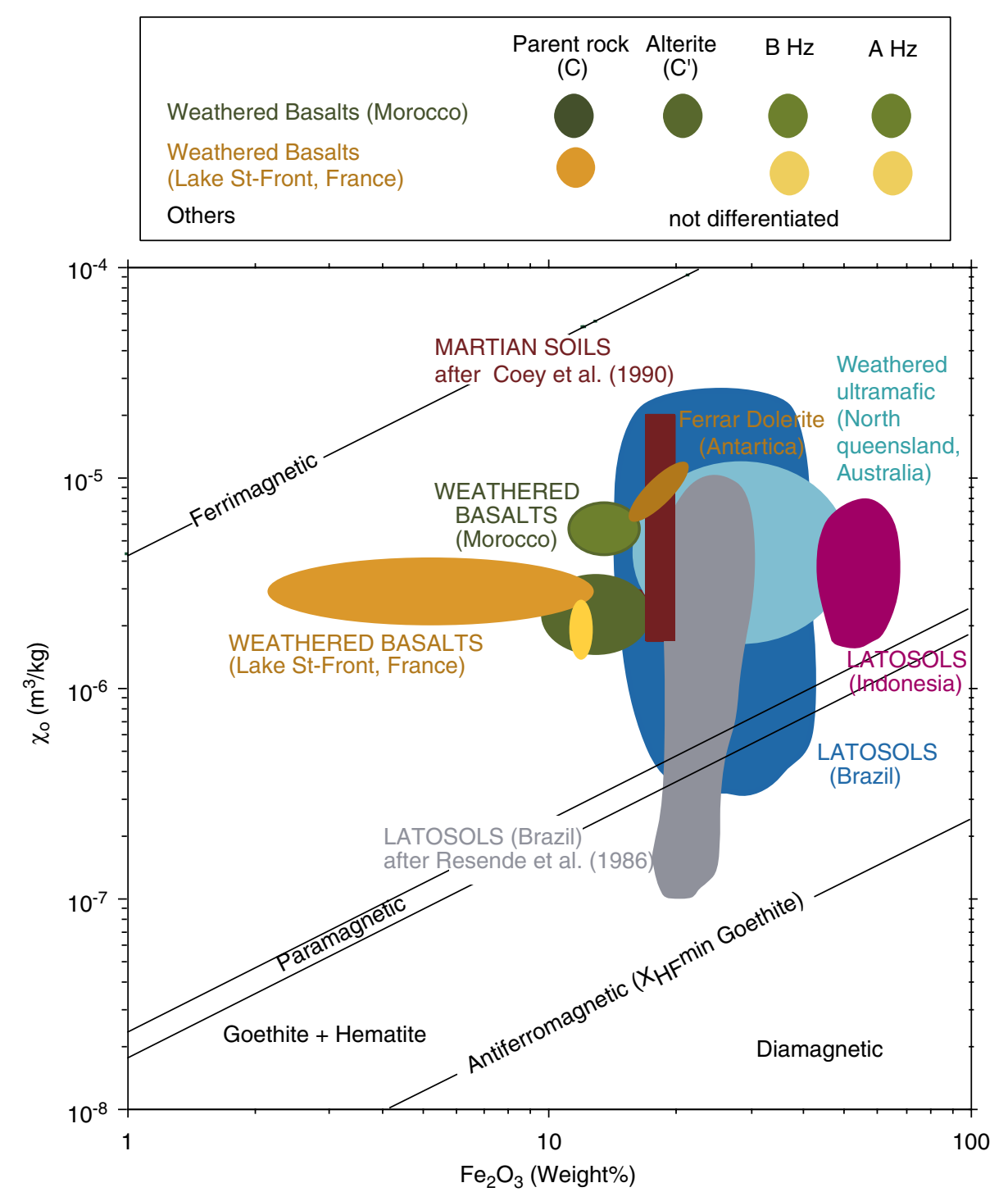

Fig. 11. Comparison of martian and terrestrial soils in a plot of low-field magnetic susceptibility $X_{\mathrm{HF}}$ versus iron content (in wt $\% \mathrm{Fe}_{2} \mathrm{O}_{3}$ ). $\mathrm{Main}_{\mathrm{ing}}$ matic behaviours and associated phases are indicated. Martian soils data after Coey et al. (1990). Graph redrawn and modified after Mathé et al. (1997).

(chlorine and bromine) present in the soils and weathered rocks (Haskin et al., 2005; Yen et al., 2005). This hypothesis is extremely similar to the acid fog hypothesis supposed to be responsible for the cementing sulphates in the soil (Banin et al., 1997; Bibring et al., 2005), and the weathering varnishes on Gusev Crater rocks (Hurowitz et al., 2006).

The second mechanism has been developed more specifically for Mars, using gas-solid reactions, through thermodynamic models and experimentations (Booth and Kieffer, 1978; Gooding, 1978). This kind of mechanism is not used on the Earth because the alteration reactions run much faster as soon as the water interferes as a media of ionic transfer. However, the solid-gas reactions may be efficient in the conditions prevailing today on Mars. The transition between the two mechanisms is essentially a problem of water activity. In the low water activity of present day Mars, the main factor responsible for weathering may be the large transfer of water occurring at high latitudes and linked to obliquity variations of Mars (Head et al., 2005; Levrard et al., 2004). In the period where ice accumulated near the poles, a small part of this water could serve as a media to provide slow and limited alteration. At a seasonal timescale, a similar process could be responsible for the sulphate (gypsum) formations observed close to the north polar cap (Langevin et al., 2005). In periods of higher obliquity, ice is destibilised and transferred to lower latitudes, as evidenced by observations of glacier deposits on several volcanoes flancs (Head and Marchant, 2003; Head et al., 2006; Milkovich et al., 2006; Shean et al., 2005). Such locations would be susceptible to undergo local weathering due to the precipitations of ice that are responsible for the formation of the glaciers (Forget et al., 2006). Alternatively, solid-gas reactions could be efficient on the whole surface of Mars, especially when considering the strong oxidant species present on the surface, and probably 


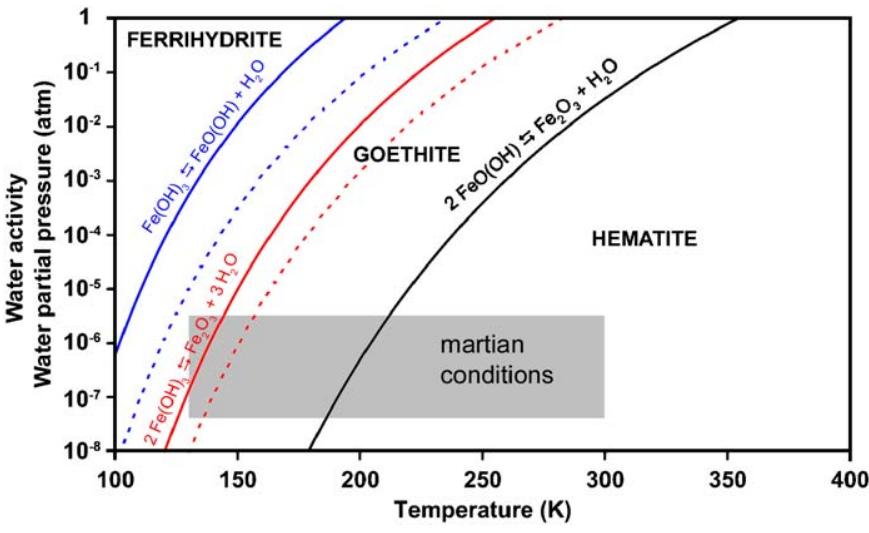

Fig. 12. Diagram of thermodynamic equilibrium curves of relevant iron oxides (ferrihydrite/goethite, ferrihydrite/haematite and goethite/haematite reactions) as a function of water vapour activity and temperature, calculated using the integrated form of the Clausius-Clapeyron equation, assuming no significant variation of enthalpies $\Delta H^{\circ}$ r in the studied range of temperatures (Gooding (1978)). The martian surface conditions (temperature and water partial pressure) are also represented. For ferrihydrite reactions, full lines are for ferrihydrite $-2 \mathrm{~L}$ and dashed lines for ferrihydrite - 6L. Data for goethite and ferrihydrite: Majzlan et al. (2003); Majzlan et al. (2004), and for haematite and water: Cox et al. (1989).

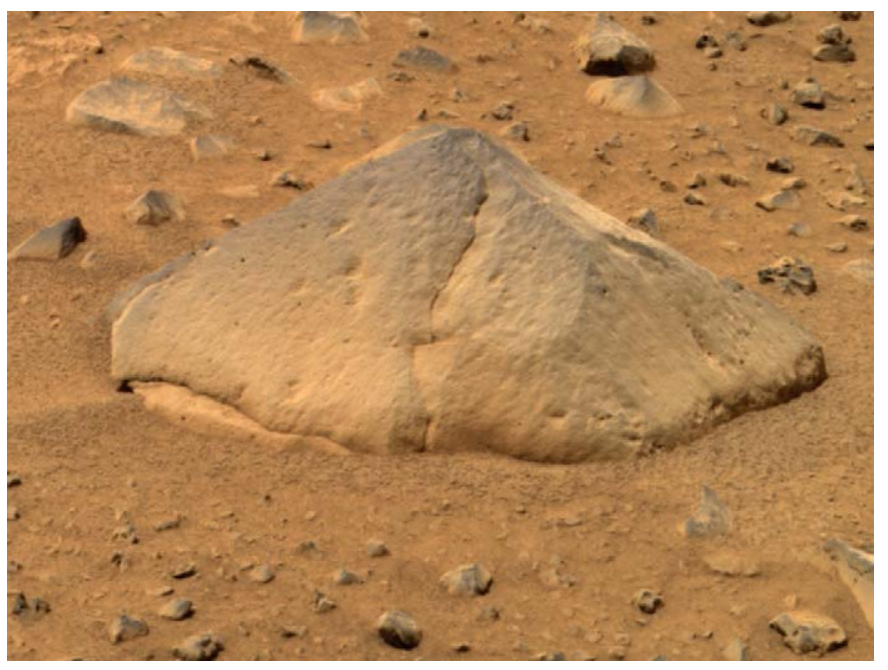

Fig. 13. Pancam picture of Adirondack rock in Gusev Crater. Credit: NASA/JPL/Cornell.

resulting from a strong coupling between the regolith and the atmosphere, through adsorption mechanisms (Zent et al., 2001; Zent and Quinn, 1995). Nevertheless, the interaction of these strong oxidants with the soil may have also processed though films of liquid water. It must be stressed that in both cases (liquid water films and/or solid-gas reactions) newly formed phases should be extremely small and poorly crystalline (Banin, 1996; Banin et al., 1993). Such a process is also consistent with the general abundance of primary phases (pyroxene, olivine) also present in the soil. Such mechanism(s) could explain the formation of the dry, but oxidised, fine grained bright dust layer on the surface of the basaltic sand (Catling, 2005; Goetz et al., 2005; Yen et al., 2005). Moreover, UV-induced dehydroxylation of iron (oxy)hydroxides (goethite and lepidocrocite) has been tested, but has not given any probing result (Morris, 1981; Morris and Lauer, 1981; Yen et al., 1999). Nevertheless, these works specify the very slow kinetics of such a process, about 1 Gyr. Thus, weathering on present-day Mars is probably an efficient process but at very long timescales (probably about $1 \mathrm{Gyr}$ ) and occurring through films of liquid water and/or gas-solid reaction.

When considering present-day weathering on Mars, aeolian activity must be taken in consideration for two effects: first it tends to homogenise the soil on a global scale, as indicate the similar compositions of all landing sites from Viking to MER (Gellert et al., 2004; Rieder et al., 2004)), but at the same time it allows erosion of the weathered surfaces and thus continuous exposure of fresh surfaces, especially today. Many rocks, such as Adirondack in Gusev Crater (Fig. 13) show indeed evidence for shape related to wind abrasion (Greeley et al., 2006). Therefore, some of the sulphates observed in the present day soil could result from aeolian erosion of ancient sulphate deposits (i.e. Meridiani Planum) further mixed with recent regolith. This can also explain the presence of $\mathrm{Fe}$-rich olivine on the surface, which is often interpreted as a limited action of water on the surface of Mars (Christensen et al., 2003; Morris et al., 2004), because of its weak resistance to alteration in aqueous conditions. In that case, olivine indicates heterogeneities in weathering on the surface, because of limited action of water since at least the last 3 Byr.

\section{Conclusions}

With the recent large amount of new data and observations provided by MER landers and Mars Express orbiter, the mineralogy of the martian surface reveals a remarkable complexity (Fig. 14). Some geological units seem to result from process similar to those occurring on the Earth, in the mineralogy and probably in the formation process (i.e. formation of red soils). Other units seem to reflect processes not dominant on the Earth and contrarily typical of the martian surface, mostly linked to the replacement of carbonates by sulphates in sedimentary cycles. These observations demonstrate the distinctness of Mars in its evolution, but also the predominant role of water. Weathering process acts as the dominant agent of the surface evolution, even if one must consider variations in space, i.e. in latitude due to climatic effect, and locally depending on the volcanic and geological activity, but also in time due to the global evolution of the atmosphere composition and water activity. In addition, various factors modify the products of weathering, i.e. volcanism, hydrothermalism, meteoritic bombardment and aeolian activity.

The MER Opportunity landing site in Meridiani Planum has been the first clear evidence for chemical activity of 

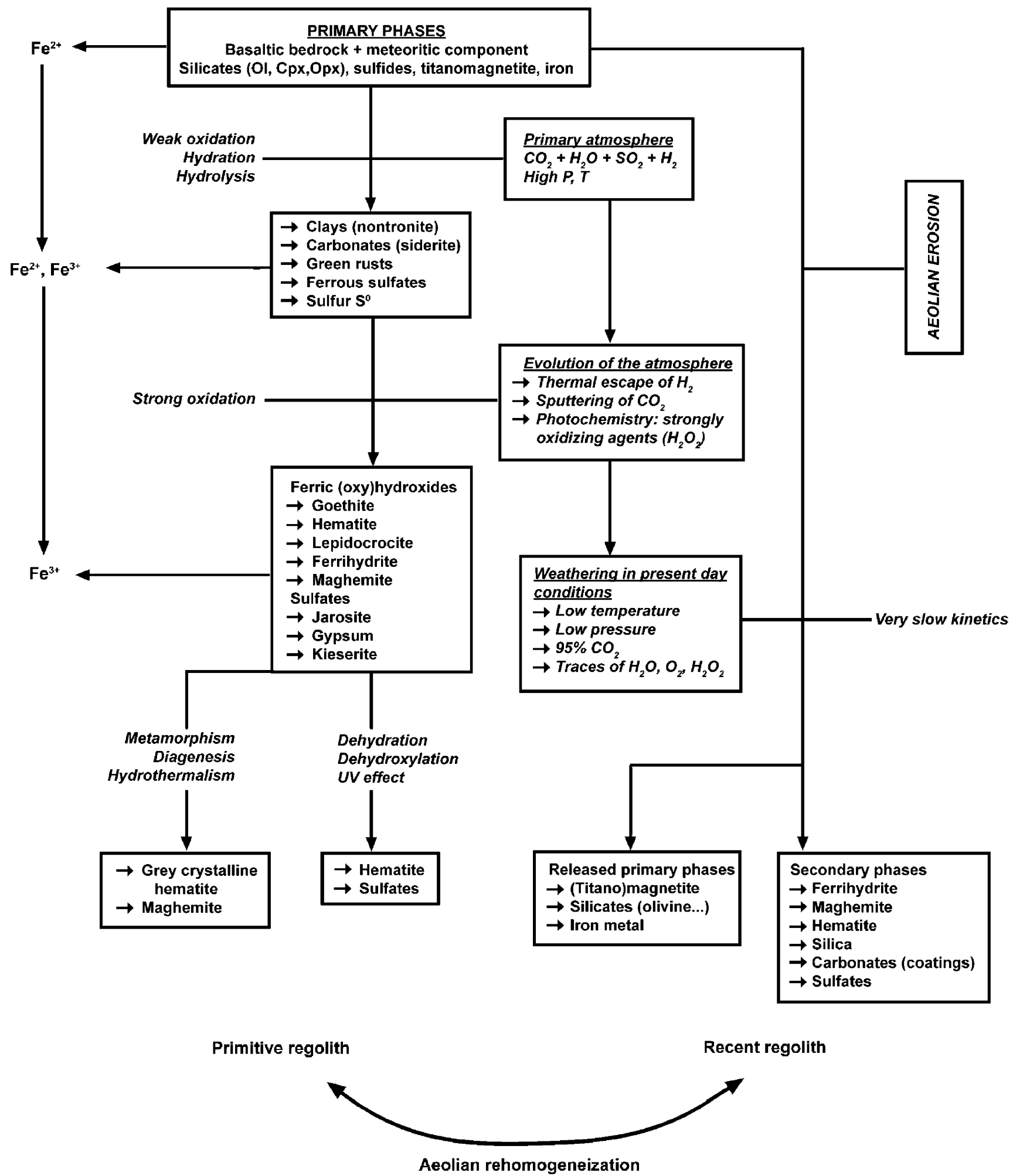

Fig. 14. A possible synthesis scheme of the various mineralogical pathways depending on the surface conditions (primary vs. present day atmosphere) and processes described. Only the major phases, described in the literature, are represented.

water on Mars, followed by MER Spirit observations in Columbia Hills and Mars Express OMEGA observations of sulphate deposits. However, many studies tend to indicate that this corresponds rather to the local interaction with catastrophic floods induced by volcanic activity. This local and limited action of water could also explain the apparent complexity and variety of these formations (from nearly unaltered to extensively transformed, at the scale of a few meters). Therefore, these observations tend to show that the Hesperian age on Mars was characterised by local 
and limited action of water on the surface, depending on regional geodynamic activity. This could be also the same for an important part of the sulphate formations observed on Mars, since nearly all these deposits are localised in Hesperian aged terrains.

Recently Mars Express OMEGA has evidenced large deposits of clay minerals on the Noachian crust. These phases are typical of temperate to tropical weathering processes on the Earth, as their formation requires abundant liquid water, and especially a long timescale action of this water. Depending on their abundance in the old Noachian crust, these clays could represent the main indicator of primary martian weathering in an $\mathrm{H}_{2} \mathrm{O}$-rich atmosphere. This hypothesis, if confirmed, could raise a new view of the evolution of the martian surface, roughly in three steps. The first would correspond to weathering process leading to clays in the Noachian, under a probable thick $\mathrm{H}_{2} \mathrm{O} / \mathrm{CO}_{2}$-rich atmosphere, similar to terrestrial-type weathering processes, i.e. high water-to-rock ratio with alteration, leaching, transport and deposition. This period could have been eventually favourable to the formation of carbonates. Then, during the Hesperian when water became scarcer and its activity sporadic, depending on volcanic activity, strongly acidic sulphate-type weathering process would have been predominant (i.e. low water-torock ratio). The third period would be like today (roughly in the Amazonian), a very slow weathering in cold and dry conditions, mainly by solid-gas or solid-films of water induced by frost-thaw and/or acid fog, favoring poorly crystalline phases, mainly iron (oxy)hydroxides. These weathering processes would be promotted by strongly oxidising agents $\left(\mathrm{H}_{2} \mathrm{O}_{2}, \mathrm{O}_{2}\right)$ and by the transfer of ice during periods of higher obliquity. But in this scenario many questions remain about the transition between these processes, and also especially about the factors affecting the evolution of the weathering process. The formation of films of liquid water remains an important hypothesis for weathering in present-day conditions. An important question concerns how the progressive loss of water from Mars forced conditions to become more acidic and more oxidising. A correlated issue concerns the impact of the martian dynamo on the evolution of the surface conditions, as it provides the main shield against atmospheric erosion by solar wind.

Many studies have focussed on extreme environments for the search of biological analogues of potential martian life. However, extremophile organisms result usually from the evolution of previous organisms obliged to adapt to more and more extreme conditions. Similarly, it is widely accepted that primitive life on Earth formed in the oceans, a quite "temperate" media. Therefore, on Mars the search for possible biological activity should start from the most primitive conditions where water could have been abundant during an extended period of time and conditions favourable to the emergence of life, i.e. the south Noachian crust. Clay minerals represent the main indicators of such a favourable environment.

\section{Aknowledgements}

The authors would like to thank Pr. Derek Sears, Julie Chittenden and the anonymous reviewer for having read this manuscript and for their useful suggestions to improve its quality. We thank also Pr. J. Bandfield, Pr. J.P. Bibring and Pr. U. Schwertmann for providing some of the figures present in this paper.

\section{References}

Allan, J.E.M., Coey, J.M.D., Resende, M., Fabris, J.D., 1988. Magnetic properties of iron-rich oxisols. Phys. Chem. Miner. 15, 470-475.

Arslan, C., Arslan, F., 2003. Thermochemical review of jarosite and goethite stability regions at 25 and $95^{\circ} \mathrm{C}$. Turkish J. Eng. Environ. Sci. 27, 45-52.

Baird, A.K., Toulmin III, P., Clark, B.C., Rose Jr., H.J., Keil, K., Christian, R.P., Gooding, J.L., 1976. Mineralogic and petrologic implications of Viking geochimical results from Mars: interim report. Science 194 (4271), 1288-1293.

Baker, L.L., Agenbroad, D.J., Wood, S.A., 2000. Experimental hydrothermal alteration of a martian analog basalt: implications for martian meteorites. Meteorit. Planet. Sci. 35, 31-38.

Baldridge, A.M., Calvin, W.M., 2004. Hydratation state of the Martian coarse-grained hematite exposures: implications for their origin and evolution. J. Geophys. Res. 109 (E04S90).

Ballou, E.V., Wood, P.C., Wydeven, T., Lehwalt, M.E., Mack, R.E., 1978. Chemical interpretation of Viking lander 1 life detection experiment. Nature 271, 644-645.

Bandfield, J.L., 2002. Global mineral distribution on Mars. J. Geophys. Res. 107 (E6), \#5042.

Bandfield, J.L., Hamitlon, V.E., Christensen, P.R., 2000. A global view of Martian surface compositions from MGS-TES. Science 287, 1626-1630.

Bandfield, J.L., Glotch, T.D., Christensen, P.R., 2003. Spectroscopic identification of carbonate minerals in the Martian dust. Science 301 (5636), 1084-1087

Bandfield, J.L., Hamilton, V.E., Christensen, P.R., McSween Jr., H.Y., 2004. Identification of quartzofeldspathic materials on Mars. J. Geophys. Res. 109 (E10009).

Banin, A., 1996. The missing crystalline minerals in Mars soils. Adv. Space Res. 18 (12), 12233-12240.

Banin, A., Ben-Schlomo, T., Margulies, L., Blake, D.F., Mancinelli, L., Gehring, E.U., 1993. The nanophase iron mineral(s) in Mars soil. J. Geophys. Res. 98 (E11), 20831-20853.

Banin, A., Han, F.X., Cicelsky, A., 1997. Aciditic volatiles and the Mars soil. J. Geophys. Res. 102 (E6), 13341-13356.

Baron, D., Palmer, C.D., 1996. Solubility of jarosite at $4-35^{\circ}$ C. Geochim. Cosmochim. Acta 60 (2), 185-195.

Barron, V., Torrent, J., 2002. Evidence for a simple pathway to maghemite in Earth and Mars soils. Geochim. Cosmochim. Acta 66 (15), 2801-2806.

Bell III, J.F., McCord, T.B., Owensby, P.D., 1990. Observational evidence of crystalline iron oxides on Mars. J. Geophys. Res. 95 (B9), 14447-14461.

Bell III, J.F., Morris, R.V., Adams, J.B., 1993. Thermally altered palagonitic tephra: a spectral and process analog to the soil and dust of Mars. J. Geophys. Res. 98 (E2), 3373-3385.

Bell III, J.F., McSween Jr., H.Y., Crisp, J.A., Morris, R.V., Murchie, S.L., Bridges, N.T., Johnson, J.R., Britt, D.T., Golombek, M.P., Moore, H.J., Ghosh, A., Bishop, J.L., Anderson, R.C., Brückner, J., Economou, T., Greenwood, J.P., Gunnlaugsson, H.P., Hargraves, R.M., Hviid, S., Knudsen, J.M., Madsen, M.B., Reid, R., Rieder, R., Soderblom, L., 2000. Mineralogic and compositional properties of Martian soil and dust: results from Mars Pathfinder. J. Geophys. Res. 105 (E1), 1721-1755. 
Bender Koch, C., Morup, S., Madsen, M.B., Vistisen, L., 1995. Ironcontaining products of basalt in a cold-dry climate. Chemical Geol. 122, 109-119.

Benning, L.G., Wilkin, R.T., Barnes, H.L., 2000. Reaction pathways in the Fe-S system below $100^{\circ} \mathrm{C}$. Chemical Geol. 167, 25-51.

Bertelsen, P., Goetz, W., Madsen, M.B., Klinch, K.M., Hviid, S.F., Knudsen, J.M., Gunnlaugsson, H.P., Merrison, J., Nornberg, P., Squyres, S.W., Bell III, J.F., Herkenhoff, K.E., Gorevan, S., Yen, A.S., Myrick, T., Klingelhöfer, G., Rieder, R., Gellert, R., 2004. Magnetic properties experiments on the Mars exploration rover spirit at gusev crater. Science 305 (5685), 827-829.

Bibring, J.-P., Langevin, Y., Gendrin, A., Gondet, B., Poulet, F., Berthé, M., Soufflot, A., Arvidson, R., Mangold, N., Mustard, J., Drossart, P., team, O., 2005. Mars surface diversity as revealed by the OMEGA/ Mars express observations. Science 307, 1576-1581.

Biemann, K., Oro, J., Toulmin III, P., Orgel, L.E., Nier, A.O., Anderson, D.M., Simmonds, P.G., Flory, D., Diaz, A.V., Rushneck, D.R., Biller, J.A., 1976. Search for organic and volatile inorganic compounds in two surface samples from the Chryse Planitia region of Mars. Science 194 (4260), 72-76.

Bigham, J.M., Schwertmann, U., Traina, S.J., Winland, R.L., Wolf, M., 1996. Schwertmannite and the chemical modeling of iron in acid sulfate waters. Geochim. Cosmochim. Acta 60 (12), 2111-2121.

Bish, D.L., Carey, J.W., Vaniman, D.T., Chipera, S.J., 2003. Stability of hydrous minerals on the Martian surface. Icarus 164, 96-103.

Bishop, J.L., Pieters, C.M., 1995. Low-temperature and low atmospheric pressure infrared reflectance spectroscopy of Mars soil analog materials. J. Geophys. Res. 100 (E3), 5369-5379.

Bishop, J.L., Pieters, C.M., Burns, R.G., Edwards, J.O., Mancinelli, R.L., Fröschl, H., 1995. Reflectance spectroscopy of ferric sulfate-bearing montmorillonites as Mars soil analog materials. Icarus 117, 101-119.

Bishop, J.L., Fröschl, H., Mancinelli, R.L., 1998a. Alteration processes in volcanic soils and identification of exobiologically important weathering products on Mars using remote sensing. J. Geophys. Res. 103 (E13), 31457-31476.

Bishop, J.L., Scheinost, A., Bell III, J.F., Britt, D., Johnson, J.R., Murchie, S., 1998b. Ferrihydrite - schwertmannite - silicate mixtures as a model of martian soils measured by pathfinder (abstract). Lunar Planet. Sci. XXIX, \#1803.

Bishop, J.L., Mancinelli, R.L., Olsen, M., Wagner, P.A., Zent, A.P., 2000. Ferrihydrite alteration to magnetite, maghemite and hematite: implications for iron oxides on Mars. Lunar Planet. Sci. XXXI, \#1946.

Bland, P.A., Smith, T.B., 2000. Meteorite accumulation on Mars. Icarus 144, 21-26.

Booth, M.C., Kieffer, H.H., 1978. Carbonate formation in Marslike environment. J. Geophys. Res. 83 (B4), 1809-1815.

Borg, L., Drake, M.J., 2005. A review of meteorite evidence for the timing of magmatism and of surface or near-surface liquid water on Mars. J. Geophys. Res. 110 (E12S03).

Boslough, M.B., Venturini, E.L., Graham, R.A., Williamson, D.L., 1986. Physical properties of shocked and thermally altered nontronite: implications for the martian surface. J. Geophys. Res. 91 (B13), E207-E214.

Bridges, J.C., Grady, M.M., 2000. Evaporite mineral assemblages in the nakhlite (martian) meteorites. Earth Planet. Sci. Lett. 176, 267-279.

Bridges, J.C., Catling, D.C., Saxton, J.M., Swindle, T.D., Lyon, I.C., Grady, M.M., 2001. Alteration assemblages in Martian meteorites: implications for near-surface processes. Space Sci. Rev. 96, 365-392.

Brimhall, G.H., Dietrich, W.E., 1987. Constitutive mass balance relations between chemical composition, volume, density, porosity, and strain in metasomatic hydrochemical systems: results on weathering and pedogenesis. Geochim. Cosmochim. Acta 51 (3), 567-587.

Bullock, M.A., Moore, J.M., Mellon, M.T., 2004. Laboratory simulations of Mars aqueous geochemistry. Icarus 170, 404-423.

Burns, R.G., 1980a. Does feroxyhyte occur on the surface of Mars? Nature 285, 647.

Burns, R.G., 1980b. Reply to Towe, 1980. Nature 288, 196.
Burns, R.G., 1988. Sulfide mineralization: its role in chemical weathering of Mars (abstract). Lunar and Planetary Institute, Workshop on Mars Sample Return Science, 48-50.

Burns, R.G., 1993. Rates and mechanisms of chemical weathering of ferromagnesian silicate minerals on Mars. Geochim. Cosmochim. Acta 57, 4555-4574.

Burns, R.G., 1994. Schwertmannite on Mars: deposition of this ferric oxyhydroxysulfate mineral in acidic saline meltwaters (abstract) Lunar Planet. Sci. XXV, 203-204.

Burns, R.G., Fisher, D.S., 1990a. Chemical evolution and oxidative weathering of magmatic iron sulfides on Mars (abstract). Lunar Planet. Sci. XXI, 145-146.

Burns, R.G., Fisher, D.S., 1990b. Evolution of sulfide mineralization on Mars. J. Geophys. Res. 95 (B9), 14169-14173.

Burns, R.G., Fisher, D.S., 1990c. Iron-sulfur mineralogy of Mars: magmatic evolution and chemical weathering products. J. Geophys. Res. 95 (B9), 14415-14421.

Burns, R.G., Fisher, D.S., 1993. Rates of oxidative weathering on the surface of Mars. J. Geophys. Res. 98 (E2), 3365-3372.

Calvin, W.M., King, T.V.V., Clark, R.N., 1994. Hydrous carbonates on Mars?: evidence from Mariner 6/7 infrared spectrometer and groundbased telescopic spectra. J. Geophys. Res. 99 (E7), 14659-14675.

Catling, D.C., 1999. A chemical model for evaporites on early Mars: possible sedimentary tracers of the early climate and implications for exploration. J. Geophys. Res. 104 (E7), 16453-16469.

Catling, D.C., 2004. On Earth, as it is on Mars? Nature 429 (6993), $707-708$.

Catling, D.C., 2005. Twin studies on Mars. Nature 436, 42-73.

Catling, D.C., Moore, J.M., 2003. The nature of coarse-grained crystalline hematite and its implications for the early environment of Mars. Icarus $165,277-300$.

Catling, D.C., Zahnle, K.J., McKay, C.P., 2001. Biogenic methane, hydrogen escape, and the irreversible oxidation of early Earth. Science 293, 839-843.

Chan, M.A., Beitler, B., Parry, W.T., Ormö, J., Komatsu, G., 2004 A possible terrestrial analogue for haematite concretions on Mars. Nature 429 (6993), 731-734.

Chevrier, V., Mathé, P.E., Rochette, P., Gunnlaugsson, H.P., 2006. Magnetic study of an antarctic weathering profile on basalt: implications for recent weathering on Mars. Earth Planet. Sci. Lett. 244, 501-514.

Chevrier, V., Rochette, P., Mathé, P.-E., Grauby, O., 2004. Weathering of iron rich phases in simulated Martian atmospheres. Geology 32 (12), 1033-1036.

Christensen, P.R., Banfield, J.L., Clark, R.N., Edgett, K.S., Hamilton, V.E., Hoefen, T., Kieffer, H.H., Kuzmin, R.O., Lane, M.D., Malin, M.C., Morris, R.V., Pearl, J.C., Pearson, R., Roush, T.L., Ruff, S.W., Smith, M.D., 2000. Detection of crystalline hematite mineralization on Mars by the thermal emission spectrometer: evidence for near-surface water. J. Geophys. Res. 105 (E4), 9623-9642.

Christensen, P.R., Morris, R.V., Lane, M.D., Bandfield, J.L., Malin, M.C., 2001. Global mapping of Martian hematite mineral deposits: remnants of water-driven processes on early-Mars. J. Geophys. Res. 106 (E10), 23873-23885.

Christensen, P.R., Bandfield, J.L., Bell III, J.F., Gorelick, N., Hamilton, V.E., Ivanov, A., Jakosky, B.M., Kieffer, H.H., Lane, M.D., Malin, M.C., McConnochie, T., McEwen, A.S., McSween Jr., H.Y., Mehall, G.L., Moersch, J.E., Nealson, K.H., Rice Jr., J.W., Richardson, M.I., Ruff, S.W., Smith, M.D., Titus, T.N., Wyatt, M.B., 2003. Morphology and composition of the surface of Mars: Mars Odyssey THEMIS results. Science 300, 2056-2061.

Christensen, P.R., Ruff, S.W., Fergason, R.L., Knudson, A.T., Anwar, S., Arvidson, R.E., Bandfield, J.L., Blaney, D.L., Budney, C., Calvin, W.M., Glotch, T.D., Golombek, M.P., Gorelick, N., Graff, T.G., Hamilton, V.E., Hayes, A., Johnson, J.R., McSween Jr., H.Y., Mehall, G.L., Mehall, L.K., Moersch, J.E., Morris, R.V., Rogers, A.D., Smith, M.D., Squyres, S.W., Wolff, M.J., Wyatt, M.B., 2004a. Initial results 
from the Mini-TES experiment in Gusev Crater from the Spirit Rover. Science 305 (5685), 837-842.

Christensen, P.R., Wyatt, M.B., Glotch, T.D., Rogers, A.D., Anwar, S., Arvidson, R.E., Bandfield, J.L., Blaney, D.L., Budney, C., Calvin, W.M., Fallacaro, A., Fergason, R.L., Gorelick, N., Graff, T.G., Hamilton, V.E., Hayes, A.G., Johnson, J.R., Knudson, A.T., McSween Jr., H.Y., Mehall, G.L., Mehall, L.K., Moersch, J.E., Morris, R.V., Smith, M.D., Squyres, S.W., Ruff, S.W., Wolff, M.J., 2004b. Mineralogy at meridiani planum from the mini-TES experiment on the opportunity rover. Science 306, 1733-1739.

Clancy, R.T., Sandor, B.J., Moriarty-Schieven, G.H., 2004. A measurement of the $362 \mathrm{GHz}$ absorption line of Mars atmospheric $\mathrm{H}_{2} \mathrm{O}_{2}$. Icarus 168 (1), 116-121.

Clark, B.C., Baird, A.K., 1979. Is the Martian lithosphere sulfure rich? J. Geophys. Res. 84 (B14), 8395-8403.

Clark, B.C., Baird, A.K., Rose Jr., H.J., Toulmin III, P., Keil, K., Castro, A.J., Kelliher, W.C., Rowe, C.D., Evans, P.H., 1976. Inorganic analyses of Martian surface samples at the Viking landing sites. Science 194 (4271), 1283-1288.

Clark, B.C., Morris, R.V., McLennan, S.M., Gellert, R., Jolliff, B., Knoll, A.H., Squyres, S.W., Lowenstein, T.K., Ming, D.W., Tosca, N.J., Yen, A., Christensen, P.R., Gorevan, S., Brückner, J., Calvin, W., Dreibus, G., Farrand, W., Klingelhoefer, G., Waenke, H., Zipfel, J., Bell III, J.F., Grotzinger, J., McSween Jr., H.Y., Rieder, R., 2005. Chemistry and mineralogy of outcrops at Meridiani Planum. Earth Planet. Sci. Lett. 240, 73-94.

Coey, J.M.D., Morup, S., Madsen, M.B., Knudsen, J.M., 1990. Titanomaghemite in magnetic soils on Earth and Mars. J. Geophys. Res. 95 (B9), 14423-14425.

Cox, J.D., Wagman, D.D., Medvedev, V.A., 1989. CODATA Key Values for Thermodynamics. Hemisphere Publishing Corp, New York.

Cudennec, Y., Lecerf, A., 2005. Topotactic transformations of goethite and lepidocrocite into hematite and maghemite. Solid State Sci. 7, $520-529$.

Dickinson, W.W., Rosen, M.R., 2003. Antarctic permafrost: an analogue for water and diagenetic minerals on Mars. Geology 31 (3), 199-202.

Dyar, M.D., Scheafer, M.W., 2004. Mössbauer spectroscopy on the surface of Mars: constraints and expectations. Earth Planet. Sci. Lett. $218,243-259$

Economou, T., 2001. Chemical analyses of martian soil and rocks obtained by the pathfinder alpha proton X-ray spectrometer. Radiat. Phys. Chem. 61, 191-197.

Eggleton, R.A., Foudoulis, C., Varkevisser, D., 1987. Weathering of basalt: changes in rock chemistry and mineralogy. Clays Clay Miner $35,161-169$.

Encrenaz, T., Bézard, B., Greathouse, T.K., Richter, M.J., Lacy, J.H., Atreya, S.K., Wong, A.S., Lebonnois, S., Lefèvre, F., Forget, F., 2004. Hydrogen peroxide on Mars: evidence for spatial and seasonal variations. Icarus $170,424-429$

Evans, D.L., Adams, J.B., 1980. Amorphous gels as possible analogs to Martian weathering products. Proc. Lunar Planet. Sci. 11, 757-763.

Fairen, A.G., Fernandez-Remolar, D., Dohm, J.M., Baker, V.R., Amils, R., 2004. Inhibition of carbonate synthesis in acidic oceans on Early Mars. Nature 431, 423-426.

Farquhar, J., Thiemens, M.H., 2000. Oxygen cycle of the Martian atmosphere-regolith system: $\Delta^{17} \mathrm{O}$ of secondary phases in Nakhla and Lafayette. J. Geophys. Res. 105 (E5), 11991-11997.

Farquhar, J., Thiemens, M.H., Jackson, T., 1998. Atmosphere-surface interactions on Mars: $\Delta^{17} \mathrm{O}$ measurements of carbonate from ALH84001. Science 280 (5369), 1580-1582.

Farquhar, J., Savarino, J., Jackson, T.L., Thiemens, M.H., 2000. Evidence of atmospheric sulphur in the martian regolith from sulphur isotopes in meteorites. Nature 404, 50-52.

Feldman, W.C., Prettyman, T.H., Maurice, S., Plaut, J.J., Bish, D.L., Vaniman, D.T., Mellon, M.T., Metzger, A.E., Squyres, S.W., Karunatillake, S., Boynton, W.V., Elphic, R.C., Funsten, H.O., Lawrence, D.J., Tokar, R.L., 2004. Global distribution of near-surface hydrogen on Mars. J. Geophys. Res. 109, E09006.
Fernandez-Remolar, D.C., Rodriguez, N., Gomez, F., Amils, R., 2003. Geological record of an acidic environment driven by iron hydrochemistry: the Rio Tinto River system. J. Geophys. Res. 108 (E7).

Fernandez-Remolar, D., Gomez-Elvira, J., Gomez, F., Sebastian, E., Martiin, J., Manfredi, J.A., Torres, J., Gonzalez Kesler, C., Amils, R., 2004. The Tinto River, an extreme acidic environment under control of iron, as an analog of the Terra Meridiani hematite site of Mars. Planet. Space Sci. 52, 239-248.

Fernandez-Remolar, D.C., Morris, R.V., Gruener, J.E., Amils, R., Knoll, A.H., 2005. The Rio Tinto Basin, Spain: mineralogy, sedimentary geobiology, and implications for interpretation of outcrop rocks at Meridiani Planum, Mars. Earth Planet. Sci. Lett. 240, 149-167.

Fialips, C.I., Carey, J.W., Vaniman, D.T., Bish, D.L., Feldman, W.C., Mellon, M.T., 2005. Hydration state of zeolites, clays, and hydrated salts under present-day martian surface conditions: can hydrous minerals account for Mars Odyssey observations of near-equatorial water-equivalent hydrogen? Icarus 178, 74-83.

Flynn, G.J., McKay, D.S., 1990. An assessment of the meteorite contribution to the Martian soil. J. Geophys. Res. 95, 14497-14509.

Foley, C.N., Economou, T., Clayton, R.N., 2003. Final chemical results from the Mars Pathfinder alpha proton X-ray spectrometer. J. Geophys. Res. 108 (E12), \#8096.

Forget, F., Haberle, R.M., Montmessin, F., Levrard, B., Head, J.W., 2006. Formation of glaciers on Mars by atmospheric precipitation at high obliquity. Science 311, 368-371.

Forget, F., Pierrehumbert, R.T., 1997. Warming early Mars with carbon dioxide clouds that scatter infrared radiation. Science 278, 1273-1276.

Gattacceca, J., Rochette, P., Bourot-Denise, M., 2003. Magnetic properties of a freshly fallen LL ordinary chondrite: the Bensour meteorite. Phys. Earth. Planet. Int. 140 (4), 343-358.

Gellert, R., Rieder, R., Anderson, R.C., Brückner, J., Clark, B.C., Dreibus, G., Economou, T., Klingelhöfer, G., Lugmair, G.W., Ming, D.W., Squyres, S.W., d'Uston, C., Wänke, H., Yen, A., Zipfel, J., 2004. Chemistry of rocks and soils in gusev crater from the alpha particle X-ray spectrometer. Science 305 (5685), 829-832.

Gellert, R., Rieder, R., Brückner, J., Clark, B.C., Dreibus, G., Klingelhöfer, G., Lugmair, G., Ming, D.W., Wänke, H., Yen, A., Zipfel, J., Squyres, S.W., 2006. Alpha particle X-ray spectrometer (APXS): results from gusev crater and calibration report. J. Geophys. Res. 111 (E02S05).

Gendrin, A., Mangold, N., Bibring, J.-P., Langevin, Y., Gondet, B., Poulet, F., Bonello, G., Quantin, C., Mustard, J., Arvidson, R., LeMouélic, S., 2005. Sulfates in martian layered terrains: the OMEGA/Mars express view. Science 307, 1587-1591.

Gillet, P., Barrat, J.A., Deloule, E., Wadhwa, M., Jambon, A., Sautter, V., Devouard, B., Neuville, D., Benzerara, K., Lesourd, M., 2002. Aqueous alteration in the Northwest Africa 817 (NWA 817) martian meteorite. Earth Planet. Sci. Lett. 203 (1), 431-444.

Glotch, T.D., Christensen, P.R., 2005. Geologic and mineralogic mapping of aram chaos: evidence for a water-rich history. J. Geophys. Res. 110 (E09006).

Glotch, T.D., Morris, R.V., Sharp, T.G., Christensen, P.R., 2003. Characterization of the effects of precursor mineralogy on hematite spectra: application to Martian hematite mineralization (abstract). Lunar Planet. Sci. XXXIV, \#2008.

Glotch, T.D., Morris, R.V., Christensen, P.R., Sharp, T.G., 2004. Effect of precursor mineralogy on the thermal infrared emission spectra of hematite: application to Martian hematite mineralization. J. Geophys. Res. 109 (E07003).

Goetz, W., Bertelsen, P., Binau, C.S., Gunnlaugsson, H.P., Hviid, S.F., Kinch, K.M., Madsen, D.E., Madsen, M.B., Olsen, M., Gellert, R., Klingelhöfer, G., Ming, D.W., Morris, R.V., Rieder, R., Rodionov, D.S., de Souza Jr., P.A., Schröder, C., Squyres, S.W., Wdowiak, T., Yen, A., 2005. Indication of drier periods on Mars from the chemistry and mineralogy of atmospheric dust. Nature 436, 62-65.

Gooding, J.L., 1978. Chemical weathering on Mars. Thermodynamic stabilities of primary minerals (and their alteration products) from mafic igneous rocks. Icarus 33, 483-513. 
Gooding, J.L., Keil, K., 1978. Alteration of glass as a possible source of clay minerals on Mars. Geophys. Res. Lett. 5 (8), 727-730.

Gooding, J.L., Wentworth, S.J., Zolensky, M.E., 1991. Aqueous alteration of the Nakhla meteorite. Meteoritics 26, 135-143.

Goulart, A.T., Fabris, J.D., Filho, M.F.d.J., Coey, J.M.D., Costa, G.M.d., Grave, E.D., 1998. Iron oxides in a soil developed from basalt. Clays Clay Miner 46 (4), 369-378.

Greeley, R., Arvidson, R.E., Barlett, P.W., Blaney, D., Cabrol, N.A., Christensen, P.R., Fergason, R.L., Golombek, M.P., Landis, G.A., Lemmon, M.T., McLennan, S.M., Maki, J.N., Michaels, T., Moersch, J.E., Neakrase, L.D.V., Rafkin, S.C.R., Richter, L., Squyres, S.W., de Souza Jr., P.A., Sullivan, R.J., Thompson, S.D., Whelley, P.L., 2006. Gusev crater: wind-related features and processes observed by the Mars exploration rover spirit. J. Geophys. Res. 111 (E02S09).

Greenwood, J.P., Riciputi, L.R., Jr, H.Y.M., Taylor, L.A., 2000. Modified sulfur isotopic compositions of sulfides in the nakhlites and Chassigny. Geochim. Cosmochim. Acta 64 (6), 1121-1131.

Griffith, L.L., Shock, E.L., 1997. Hydrothermal hydration of Martian crust: illustration via geochemical model calculations. J. Geophys. Res. 102 (E4), 9135-9143.

Grotzinger, J.P., Arvidson, R.E., Bell III, J.F., Calvin, W., Clark, B.C., Fike, D.A., Golombek, M., Greeley, R., Haldemann, A., Herkenhoff, K.E., Jolliff, B.L., Knoll, A.H., Malin, M., McLennan, S.M., Parker, T., Soderblom, L., Sohl-Dickstein, J.N., Squyres, S.W., Tosca, N.J., Watters, W.A., 2005. Stratigraphy and sedimentology of a dry to wet eolian depositional system, Burns formation, Meridiani Planum, Mars. Earth Planet. Sci. Lett. 240, 11-72.

Gunnlaugsson, H.P., 2000. Analysis of the magnetic properties experiment data on Mars: results from Mars Pathfinder. Planet. Space Sci. 48, 1491-1504.

Gunnlaugsson, H.P., Weyer, G., Helgason, Ö., 2002. Titanomaghemite in Icelandic basalt: possible clues for the strongly magnetic phase in Martian soil and dust. Planet. Space Sci. 50, 157-161.

Hamilton, V.E., Christensen, P.R., 2005. Evidence for extensive, olivinerich bedrock on Mars. Geology 33 (6), 433-436.

Hamilton, V.E., Minitti, M.E., 2003. Are oxidized shergottite-like basalts an alternative to "andesite" on Mars? Geophys. Res. Lett. 30 (18).

Hamilton, V.E., Wyatt, M.B., McSween Jr., H.Y., Christensen, P.R., 2001. Analysis of terrestrial and Martian volcanic compositions using thermal emission spectroscopy 2. Application to Martian surface spectra from the Mars global surveyor thermal emission spectrometer. J. Geophys. Res. 106 (7), 14733-14746.

Hamilton, V.E., Christensen, P.R., Bandfield, J.L., 2003. Volcanism or aqueous alteration on Mars? Nature 421, 711-712.

Hargraves, R.B., Collinson, D.W., Arvidson, R.E., Spitzer, C.R., 1976 a. Viking magnetic properties investigations: further results. Science 194 (4271), 1303-1309.

Hargraves, R.B., Collinson, D.W., Spitzer, C.R., 1976b. Viking magnetic properties investigation: preliminary results. Science 194 (4260), 84-86.

Hargraves, R.B., Collinson, D.W., Arvidson, R.E., Spitzer, C.R., 1977. The viking magnetic properties experiment: primary mission results. J. Geophys. Res. 82 (28), 4547-4558.

Hargraves, R.B., Collinson, D.W., Arvidson, R.E., Gates, P.M., 1979. Viking magnetic properties experiment: extended mission results. J. Geophys. Res. 84 (B14), 8379-8384.

Hargraves, R.B., Knudsen, J.M., Bertelsen, P., Goetz, W., Gunnlaugsson, H.P., Hviid, S.F., Madsen, M.B., Olsen, M., 2000. Magnetic enhancement on the surface of Mars? J. Geophys. Res. 105 (E1), 1819-1827.

Hartmann, W.K., Malin, M., McEwen, A., Carr, M., Soderblom, L., Thomas, P., Danielson, E., James, P., Veverka, J., 1999. Evidence for recent volcanism on Mars from crater counts. Nature 397, 586-589.

Haskin, L.A., Wang, A., Jolliff, B.L., McSween Jr., H.Y., Clark, B.C., Des Marais, D.J., McLennan, S.M., Tosca, N.J., Hurowitz, J.A., Farmer, J.D., Yen, A., Squyres, S.W., Arvidson, R.E., Klingelhöfer, G., Schröder, C., de Souza Jr., P.A., Ming, D.W., Gellert, R., Zipfel, J., Brückner, J., Bell III, J.F., Herkenhoff, K., Christensen, P.R., Ruff, S., Blaney, D., Gorevan, S., Cabrol, N.A., Crumpler, L., Grant, J.,
Soderblom, L., 2005. Water alteration of rocks and soils on Mars at the spirit rover site in gusev crater. Nature 436, 66-69.

Head, J.W., Marchant, D.R., 2003. Cold-based mountain glaciers on Mars: western Arsia Mons. Geology 31 (7), 641-644.

Head, J.W., Neukum, G., Jaumann, R., Hiesinger, H., Hauber, E., Carr, M., Masson, P., Foing, B., Hoffmann, H., Kreslavsky, M., Werner, S., Milkovich, S., van Gasselt, S., HRSC Co-Investigator Team, 2005. Tropical to mid-latitude snow and ice accumulation, flow and glaciation on Mars. Nature 434, 346-351.

Head, J.W., Marchant, D.R., Agnew, M.C., Fassett, C.I., Kreslavsky, M.A., 2006. Extensive valley glacier deposits in the northern midlatitudes of Mars: evidence for Late Amazonian obliquity-driven climate change. Earth Planet. Sci. Lett. 241, 663-671.

Herkenhoff, K.E., Squyres, S.W., Arvidson, R., Bass, D.S., Bell III, J.F., Bertelsen, P., Ehlmann, B.L., Farrand, W., Gaddis, L., Greeley, R., Grotzinger, J., Hayes, A.G., Hviid, S.F., Johnson, J.R., Jolliff, B., Kinch, K.M., Knoll, A.H., Madsen, M.B., maki, J.N., McLennan, S.M., McSween Jr., H.Y., Ming, D.W., Rice Jr., J.W., Richter, L., Sims, M., Smith, P.H., Soderblom, L.A., Spanovitch, N., Sullivan, R., Thompson, S., Wdowiak, T., Weitz, C., Whelley, P., 2004. Evidence from opportunity's microscopic imager for water on meridiani planum. Science 306, 1727-1730.

Hodges Jr., R.R., 2002. The rate of loss of water from Mars. Geophys. Res. Lett. 29 (3), \#1038.

Hoefen, T.M., Clark, R.N., Bandfield, J.L., Smith, M.D., Pearl, J.C., Christensen, P.R., 2003. Discovery of olivine in the Nili Fossae region of Mars. Science 302, 627-630.

Hunt, C.P., Moscowitz, B.M., Banerjee, S.K., 1995. Magnetic properties of rocks and minerals. Rock Physics and Phase Relations, A Handbook of Physical Constants, American Geophysical Union, Minneapolis. p. 189-204.

Hurowitz, J.A., McLennan, S.M., Lindsley, D.H., Schoonen, M.A.A., 2005. Experimental epithermal alteration of synthetic Los Angeles meteorite: implications for the origin of Martian soils and identification of hydrothermal sites on Mars. J. Geophys. Res. 110 (E07002).

Hurowitz, J.A., McLennan, S.M., Tosca, N.J., Arvidson, R.E., Michalski, J.R., Ming, D.W., Schröder, C., Squyres, S.W., 2006. In situ and experimental evidence for acidic weathering of rocks and soils on Mars. J. Geophys. Res. 111 (E02S19).

Hviid, S.F., Madsen, M.B., Gunnlaugsson, H.P., Goetz, W., Knudsen, J.M., Hargraves, R.B., Smith, P., Britt, D., Dinesen, A.R., Mogensen, C.T., Olsen, M., Pedersen, C.T., Vistisen, L., 1997. Magnetic properties experiments on the Mars Pathfinder Lander: preliminary results. Science 278, 1768-1770.

Hynek, B.M., Arvidson, R.E., Phillips, R.J., 2002. Geologic setting and origin of Terra Meridiani hematite deposit on Mars. J. Geophys. Res. 107 (E10), \#5088.

Johnson, J.R., Staid, M.I., Titus, T.N., Becker, K., 2006. Shocked plagioclase signatures in thermal emission spectrometer data of Mars. Icarus 180, 60-74.

Johnson, R.E., Liu, M., 1998. Sputtering of the atmosphere of Mars. 1. Collisional dissociation of $\mathrm{CO}_{2}$. J. Geophys. Res. 103 (E2), 3639-3647.

Kahn, R., 1985. The evolution of $\mathrm{CO}_{2}$ on Mars. Icarus 62, 175-190.

King, P.L., Lescinsky, D.T., Nesbitt, H.W., 2004. The composition and evolution of primordial solutions on Mars, with application to other planetary bodies. Geochim. Cosmochim. Acta 68 (23), 4993-5008.

King, P.L., McSween Jr., H.Y., 2005. Effects of H2O, pH, and oxidation state on the stability of Fe minerals on Mars. J. Geophys. Res. 110 (E12S10).

Kirkland, L.E., Herr, K.C., 2000. Spectral anomalies in the 11 and $12 \mu \mathrm{m}$ region from the Mariner Mars 7 infrared spectrometer. J. Geophys. Res. 105 (E9), 22507-22515.

Kirschvink, J.L., Maine, A.T., Vali, H., 1997. Paleomagnetic evidence of a low-temperature origin of carbonate in the Martian meteorite ALH84001. Science 275 (5306), 1629-1633.

Klein, H.P., Horowitz, N.H., Levin, G.V., Oyama, V.I., Lederberg, J., Rich, A., Hubbard, J.S., Hobby, G.L., Straat, P.A., Berdahl, B.J., 
Carle, G.C., Brown, F.S., Johnson, R.D., 1976. The Viking biological investigations: preliminary results. Science 194 (4260), 99-105.

Klingelhöfer, G., Jr, B.F., Morris, R.V., Kankeleit, E., Held, P., Evlanov, E., Priloutskii, O., 1996. Mineralogical analysis of Martian soil and rock by a miniaturized backscattering Mössbauer spectrometer. Planet. Space Sci. 44 (11), 1277-1288.

Klingelhöfer, G., Morris, R.V., Bernhardt, B., Rodinov, D., de Souza Jr., P.A., Squyres, S.W., Foh, J., Kankeleit, E., Bonnes, U., Gellert, R., Schröder, C., Linkin, S., Evlanov, E., Zubkov, B., Prilutski, O., 2003. Athena MIMOS II Mössbauer spectrometer investigation. J. Geophys. Res. 108 (E12), \#8067, 8-11-8-18.

Klingelhöfer, G., Morris, R.V., Bernhardt, B., Schröder, C., Rodionov, D., de Souza Jr., P.A., Yen, A., Renz, F., Wdowiak, T., Squyres, S., 2004a. Mössbauer spectroscopy of soils and rocks at Gusev Crater and Meridiani Planum (abstract). Lunar Planet. Sci. XXXV, \#2184.

Klingelhöfer, G., Morris, R.V., Bernhardt, B., Schröder, S., Rodionov, D.S., de Souza Jr., P.A., Yen, A., Gellert, R., Evlanov, E.N., Zubkov, B., Foh, J., Bonnes, U., Kankeleit, E., Gütlich, P., Ming, D.W., Renz, F., Wdowiak, T., Squyres, S.W., Arvidson, R.E., 2004b. Jarosite and hematite at Meridiani Planum from opportunity's Mössbauer spectrometer. Science 306, 1740-1745.

Klingelhöfer, G., Rodionov, D.S., Morris, R.V., Schröder, C., de Souza, P.A., Ming, D.W., Yen, A.S., Bernhardt, B., Renz, F., Fleischer, I., Wdowiak, T., Squyres, S.W., and Athena Science Team, 2005. MIMOS II on MER - one year of Mössbauer spectroscopy on the surface of Mars: from jarosite at Meridiani Planum to goethite at Gusev Crater (abstract). Lunar Planet. Sci. 36, \#2349.

Knauth, L.P., Burt, D.M., Wohletz, K.H., 2005. Impact origin of sediments at the opportunity landing site on Mars. Nature 438, $1123-1128$.

Lammer, H., Stumptner, W., Bauer, S.J., 1996. Loss of H and O from Mars: implications for the planetary water inventory. Geophys. Res. Lett. 23 (23), 3353-3356.

Lammer, H., Lichtenegger, H.I.M., Kolb, C., Ribas, I., Guinan, E.F., Abart, R., Bauer, S.J., 2003. Loss of water from Mars: implications for the oxidation of the soil. Icarus 165 (1), 9-25.

Lane, M.D., Morris, R.V., Mertzman, S.A., Christensen, P.R., 2002. Evidence for platy hematite grains in Sinus Meridiani, Mars. J. Geophys. Res. 107 (E12), 5126-5140.

Lane, M.D., Dyar, M.D., Bishop, J.L., 2004. Spectroscopic evidence for hydrous iron sulfates in the Martian soil. Geophys. Res. Lett. 31, \#119702.

Langevin, Y., Poulet, F., Bibring, J.-P., Gondet, B., 2005. Sulfates in the North Polar region of Mars detected by OMEGA/Mars express. Science 307, 1584-1586.

Larsen, K.W., Arvidson, R.E., Jolliff, B.L., CLark, B.C., 2000. Correspondance and least square analyses of soil and rock compositions for the Viking Lander 1 and Pathfinder landing sites. J. Geophys. Res. 105 (E12), 29207-29221.

Leblanc, F., Luhmann, J.G., Johnson, R.E., Chassefiere, E., 2002. Some expected impacts of a solar energetic particle event at Mars. J. Geophys. Res. 107 (A5), \#1058 SIA 5-1-SIA 5-10.

Levin, G.V., Straat, P.A., 1976. Viking labeled release biology experiment: interim results. Science 194 (4271), 1322-1329.

Levrard, B., Forget, F., Montmessin, F., Laskar, J., 2004. Recent ice-rich deposits formed at high latitudes on Mars by sublimation of unstable equatorial ice during low obliquity. Nature 431, 1072-1073.

Lorand, J.P., Chevrier, V., Sautter, V., 2005. Sulfide mineralogy and redox conditions in some Shergottites. Meteorit. Planet. Sci. 40 (8), $1257-1272$

Madsen, M.B., Agerkvist, D.P., Gunnlaugson, H.P., Hviid, S.F., Knudsen, J.M., Vistisen, L., 1995. Titanium and the magnetic phase of Mars. Hyperfine Interactions 95, 291-304.

Madsen, M.B., Hviid, S.F., Gunnlaugsson, H.P., Knudsen, J.M., Goetz, W., Pedersen, C.T., Dinesen, A.R., Mogensen, C.T., Olsen, M., 1999. The magnetic properties experiment on Mars Pathfinder. J. Geophys Res. 104 (E4), 8761-8779.
Madsen, M.B., Bertelsen, P., Goetz, W., Binau, C.S., Olsen, M., Folkmann, F., Gunnlaugsson, H.P., Kinch, K.M., Knudsen, J.M., Merrison, J., Nornberg, P., Squyres, S.W., Yen, A.S., Rademacher, J.D., Gorevan, S., Myrick, T., Bartlett, P., 2003. Magnetic properties experiments on the Mars exploration rover mission. J. Geophys. Res. 108 (E12), \#8069.

Madden, M.E.E., Bodnar, R.J., Rimstidt, J.D., 2004. Jarosite as an indicator for water-limited weathering on Mars. Nature 431, 821-823.

Majzlan, J., Grevel, K.D., Navrotsky, A., 2003. Thermodynamics of iron oxides: Part II. Enthalpies of formation and relative stability of goethite $(\alpha-\mathrm{FeOOH})$, lepidocrocite $(\gamma-\mathrm{FeOOH})$, and maghemite $\left(\gamma-\mathrm{Fe}_{2} \mathrm{O}_{3}\right)$. Am. Miner. 88, 855-859.

Majzlan, J., Navrotsky, A., Schwertmann, U., 2004. Thermodynamics of iron oxides: Part III. Enthalpies of formation and stability of ferrihydrite $\left(\sim \mathrm{Fe}(\mathrm{OH})_{3}\right)$, schwertmannite $\quad\left(\sim \mathrm{FeO}(\mathrm{OH})_{3 / 4}\left(\mathrm{SO}_{4}\right)_{1 / 8}\right)$, and $\varepsilon-\mathrm{Fe}_{2} \mathrm{O}_{3}$. Geochim. Cosmochim. Acta 68 (5), 1049-1059.

Marion, G.M., Catling, D.C., Kargel, J.S., 2003. Modeling aqueous ferrous iron chemistry at low temperatures with application to Mars. Geochim. Cosmochim. Acta 67 (22), 4251-4266.

Mathé, P.-E., Rochette, P., Vlag, P., Vandamme, D., 1997. The magnetic soils of Earth: a perspective for the magnetic pad experiment on pathfinder (abstract). American Geological Union, Fall Meeting, San Fransisco, USA, December 1997.

Mathé, P.-E., Rochette, P., Vandamme, D., Colin, F., 1999. Volumetric changes in weathered profiles: iso-element mass balance method questioned by magnetic fabric. Earth Planet. Sci. Lett. 167, 255-267.

McLennan, S.M., 2003. Sedimentary silica on Mars. Geology 31 (4), 315-318.

McLennan, S.M., Bell III, J.F., Calvin, W.M., Christensen, P.R., Clark, B.C., de Souza, P.A., Farmer, J., Farrand, W.H., Fike, D.A., Gellert, R., Ghosh, A., Glotch, T.D., Grotzinger, J.P., Hahn, B., Herkenhoff, K.E., Hurowitz, J.A., Johnson, J.R., Johnson, S.S., Jolliff, B., Klingelhöfer, G., Knoll, A.H., Learner, Z., Malin, M.C., McSween Jr., H.Y., Pocock, J., Ruff, S.W., Soderblom, L.A., Squyres, S.W., Tosca, N.J., Watters, W.A., Wyatt, M.B., Yen, A., 2005. Provenance and diagenesis of the evaporite-bearing Burns formation, Meridiani Planum, Mars. Earth Planet. Sci. Lett. 240, 95-121.

McSween Jr., H.Y., 2002. The rocks of Mars, from far and near. Meteorit. Planet. Sci. 37, 7-25.

McSween Jr., H.Y., Murchie, S.L., Crisp, J.A., Bridges, N.T., Anderson, R.C., Bell III, J.F., Britt, D.T., Brückner, J., Dreibus, G., Economou, T., Ghosh, A., Colombeck, M.P., Greenwood, J.P., Johnson, J.R., Moore, H.J., Morris, R.V., Parker, T.J., Rieder, R., Singer, R., Wänke, H., 1999. Chemical, multispectral, and textural constraints on the composition and origin of rocks at the Mars Pathfinder landing site. J. Geophys. Res. 104 (E4), 8679-8715.

McSween Jr., H.Y., Wyatt, M.B., Gellert, R., Bell III, J.F., Morris, R.V., Herkenhoff, K.E., Crumpler, L.S., Milam, K.A., Stockstill, K.R., Tornabene, L.L., Arvidson, R.E., Bartlett, P., Blaney, D., Cabrol, N.A., Christensen, P.R., Clark, B.C., Crisp, J.A., Des Marais, D.J., Economou, T., Farmer, J.D., Farrand, W., Ghosh, A., Golombek, M., Gorevan, S., Greeley, R., Hamilton, V.E., Johnson, J.R., Joliff, B.L., Klingelhöfer, G., Knudson, A.T., McLennan, S., Ming, D., Moersch, J.E., Rieder, R., Ruff, S.W., Schröder, C., de Souza Jr., P.A., Squyres, S.W., Wänke, H., Wang, A., Yen, A., Zipfel, J., 2006. Characterization and petrologic interpretation of olivine-rich basalts at Gusev Crater, Mars. J. Geophys. Res. 111 (E02S10).

Michalski, J.R., Kraft, M.D., Sharp, T.G., Williams, L.B., Christensen, P.R., 2005. Mineralogical contraints on the high-silica martian surface component observed by TES. Icarus 174, 161-177.

Milkovich, S.M., Head, J.W., Marchant, D.R., 2006. Debris-covered piedmont glaciers along the northwest flank of the Olympus Mons scarp: evidence for low-latitude ice accumulation during the Late Amazonian of Mars, Icarus, in press.

Ming, D.W., Mittlefehldt, D.W., Morris, R.V., Golden, D.C., Gellert, R., Yen, A., Clark, B.C., Squyres, S.W., Farrand, W.H., Ruff, S.W., Arvidson, R.E., Klingelhöfer, G., McSween, H.Y., Rodionov, D.S., Schröder, C., de Souza Jr., P.A., Wang, A., 2006. Geochemical and 
mineralogical indicators for aqueous processes in the Columbia Hills of Gusev crater, Mars. J. Geophys. Res. 111 (E02S12).

Minitti, M.E., Lane, M.D., Bishop, J.L., 2004. A new hematite formation mechanism for Mars (abstract). Lunar Planet. Sci. 1, \#1999.

Mittlefehldt, D.W., 1994. ALH84001, a cumulate othopyroxenite member of the Martian meteorite clan. Meteoritics 29, 214-221.

Moore, J.M., 2004. Blueberry fields for ever. Nature 428 (6984), 711-712.

Moore, J.M., Bullock, M.A., 1999. Experimental studies of Mars-analog brines. J. Geophys. Res. 104 (E9), 21925-21934.

Morris, R.V., 1981. Ultra-violet radiation as a weathering agent on Mars: how important is it? abstracts of Papers presented to the Third International Colloquium on Mars, co-sponsored by the National Aeronautics and Space Administration, LPI, and the Division of Planetary Sciences of the American Astronomical Society. Held in Pasadena, California, August 31-September 2, 1981. LPI Contribution 441, published by the Lunar and Planetary Institute, 3303 Nasa Road 1, Houston, TX 77058, 163.

Morris, R.V., Golden, D.C., 1998. Goldenrod pigments and the occurence of hematite and possibly goethite in the Olympus-Amazonis region of Mars. Icarus 134 (1), 1-10.

Morris, R.V., Lauer Jr., H.V., 1981. Stability of goethite $(\alpha-\mathrm{FeOOH})$ and lepidocrocite $(\delta$-FeOOH) to dehydratation by UV radiation : implications for their occurence on the Martian surface. J. Geophys. Res. 86 (B11), 10893-10899.

Morris, R.V., Agresti, D.G., Jr, H.V.L, Newcomb, J.A., Shelfer, T.D., Murali, A.V., 1989. Evidence for pigmentary hematite on Mars based on optical, magnetic, and Mössbauer studies of superparamagnetic (nanocrystalline) hematite. J. Geophys. Res. 94 (B3), $2760-2778$.

Morris, R.V., Golden, D.C., Bell III, J.F., Jr, H.V.L, Adams, J.B., 1993. Pigmenting agents in Martian soils : inferences from spectral, Mössbauer, and magnetic properties of nanophase and other iron oxides in Hawaiian palagonitic soil PN-9. Geochim. Cosmochim. Acta 57, 4597-4609.

Morris, R.V., Golden, D.C., Bell III, J.F., 1997. Low-temperature reflectivity spectra of red hematite and the color of Mars. J. Geophys. Res. 102 (E4), 9125-9133.

Morris, R.V., Golden, D.C., Shelfer, T.D., Lauer Jr., H.V., 1998. Lepidocrocite to maghemite to hematite: a pathway to magnetic and hematitic Martian soil. Meteorit. Planet. Sci. 33, 743-751.

Morris, R.V., Golden, D.C., Bell III, J.F., Shelfer, T.D., Scheinost, A.C., Hinman, N.W., Furniss, G., Mertzman, S.A., Bishop, J.L., Ming, D.W., Allen, C.C., Britt, T., 2000. Mineralogy, composition, and alteration of Mars pathfinder rocks and soils: evidence from multispectral, elemental, and magnetic data on terrestrial analogue, SNC meteorite, and Pathfinder samples. J. Geophys. Res. 105 (E1), $1757-1817$.

Morris, R.V., Klingelhöfer, G., Bernhardt, B., Schröder, C., Rodionov, D.S., de Souza Jr., P.A., Yen, A., Gellert, R., Evlanov, E.N., Foh, J., Kankeleit, E., Gütlich, P., Ming, D.W., Renz, F., Wdowiak, T., Squyres, S.W., Arvidson, R.E., 2004. Mineralogy at Gusev Crater from the Mössbauer spectrometer on the Spirit Rover. Science 305 (5685), 833-836.

Morris, R.V., Klingelhöfer, G., Schröder, C., Rodionov, D.S., Yen, A., Ming, D.W., de Souza Jr., P.A., Fleischer, I., Wdowiak, T., Gellert, R., Bernhardt, B., Evlanov, E.N., Zubkov, B., Foh, J., Bonnes, U., Kankeleit, E., Gütlich, P., Renz, F., Squyres, S.W., Arvidson, R.E., 2006. Mössbauer mineralogy of rock, soil, and dust at Gusev crater, Mars: Spirit's journey through weakly altered olivine basalt on the Plains and pervasively altered basalt in the Columbia Hills. J. Geophys. Res. 111 (E02S13).

Morris, R.V., Ming, D.W., Graff, T.G., Arvidson, R.E., Bell III, J.F., Squyres, S.W., Mertzman, S.A., Gruener, J.E., Golden, D.C., Le, L., Robinson, G.A., 2005. Hematite spherules in basaltic tephra altered under aqueous, acid-sulfate conditions on Mauna Kea volcano, Hawaii: possible clues for the occurrence of hematite-rich spherules in the Burns formation at Meridiani Planum, Mars. Earth Planet. Sci. Lett. 240, 168-178.
Morse, J.W., Marion, G.M., 1999. The role of carbonates in the evolution of early Martian oceans. Am. J. Sci. 299, 738-761.

Moskowitz, B.M., Hargraves, R.B., 1984. Magnetic cristobalite (?): a possible new magnetic phase produced by the thermal decomposition of nontronite. Science 225 (4667), 1152-1154.

Mustard, J.F., Poulet, F., Gendrin, A., Bibring, J.-P., Langevin, Y., Gondet, B., Mangold, N., Bellucci, G., Altieri, F., 2005. Olivine and pyroxene diversity in the crust of Mars. Science 307, 1594-1597.

Nahon, D.B., 1991. Self-organization in chemical lateritic weathering. Geoderma 51, 5-13.

Nakamura, T., Tajika, E., 2001. Stability and evolution of the climate system of Mars. Earth Planets Space 53, 851-859.

Newsom, H.E., Hagerty, J.J., 1997. Chemical components of the Martian soil: melt degassing, hydrotermal alteration and chondritic debris. J. Geophys. Res. 102 (E8), 19345-19355.

Newsom, H.E., Hagerty, J.J., Goff, F., 1999. Mixed hydrothermal fluids and the origin of the Martian soil. J. Geophys. Res. 104 (E4), 8717-8728.

Noack, Y., 1981. La palagonite: caractéristiques, facteurs d'évolution et mode de formation. Bull. Minér. 104, 36-46.

Ohmoto, H., Watanabe, Y., Kumazawa, K., 2004. Evidence from massive siderite for a $\mathrm{CO}_{2}$-rich atmosphere before $\sim 1.8$ billion years ago. Nature 429 (6990), 395-399.

Ormö, J., Komatsu, G., Chan, M.A., Beitler, B., Parry, W.T., 2004. Geological features indicative of processes related to the hematite formation in Meridiani Planum and Aram Chaos, Mars: a comparison with diagenetic hematite deposits in southern Utah, USA. Icarus 171, 295-316.

Oyama, V.I., Berdahl, B.J., 1979. A model of Martian surface chemistry. J. Mol. Evol. 14, 199-210.

Oyama, V.I., Berdahl, B.J., Woeller, F., Lehwalt, M., 1978. The chemical activities of the viking biology experiments and the arguments for the presence of superoxides, peroxides, gamma-Fe2O3 and carbon suboxide polymer in the Martian soil. Life Sci. Space Res. 16, 3-8.

Papike, J.J., Karner, J.M., Shearer, C.K., 2006. Comparative planetary mineralogy: implications of martian and terrestrial jarosite. A crystal chemical perspective. Geochim. Cosmochim. Acta 70, 1309-1331.

Patel, M.R., Zarnecki, J.C., Catling, D.C., 2002. Ultraviolet radiation on the surface of Mars and the Beagle 2 UV sensor. Planet. Space Sci. 50, 915-927.

Pédro, G., 1964. Contribution à l'étude expérimentale de l'altération chimique des roches cristallines, Paris. p. 344.

Phillips, R.J., Zuber, M.T., Salomon, S.C., Golombek, M.P., Jakosky, B.M., Banerdt, W.B., Smith, D.E., Williams, R.M.E., Hynek, B.M., Aharonson, O., Hauck II, S.A., 2001. Ancient geodynamic and globalscale hydrology on Mars. Science 291, 2587-2591.

Pollack, J.B., Kasting, J.F., Richardson, S.M., Poliakoff, K., 1987. The case for a wet, warm climate on early Mars. Icarus 71 (2), 203-224.

Posey-Dowty, J., Moskowitz, B., Crerar, D., Hargraves, R., Tanenbaum, L., Dowty, E., 1986. Iron oxide and hydroxide precipitation from ferrous solutions and its relevance to Martian surface mineralogy. Icarus 66, 105-116.

Postawko, S., 1985. Sulfur dioxide and Martian surface temperatures (abstract). Lunar Planet. Sci. XVI, 673-674.

Poulet, F., Bibring, J.-P., Mustard, J.F., Gendrin, A., Mangold, N., Langevin, Y., Arvidson, R.E., Gondet, B., Gomez, C., the OMEGA Team, 2005. Phyllosilicates on Mars and implications for the early Mars history. Nature 481, 623-627.

Regenspurg, S., Brand, A., Peiffer, S., 2004. Formation and stability of schwertmannite in acidic minig lakes. Geochim. Cosmochim. Acta 68 (6), 1185-1197.

Resende, M., Allan, J., Coey, J.M.D., 1986. The magnetic soils of Brazil. Earth Planet. Sci. Lett. 78, 322-326.

Rieder, R., Economou, T., Wänke, H., Turkevich, A., Crisp, J., Brückner, J., Dreibus, G., Jr, H.Y.M., 1997. The chemical composition of martain soil and rocks returned by the mobile alpha proton X-ray spectrometer: preliminary results from the X-ray mode. Science 278, 1771-1774. 
Rieder, R., Gellert, R., Anderson, R.C., Brückner, J., Clark, B.C., Dreibus, G., Economou, T., Klingelhöfer, G., Lugmair, G.W., Ming, D.W., Squyres, S.W., d'Uston, C., Wänke, H., Yen, A., Zipfel, J., 2004. Chemistry of rocks and soils at Meridiani Planum from the alpha particle X-ray spectrometer. Science 306, 1746-1749.

Rochette, P., Lorand, J.-P., Fillion, G., Sautter, V., 2001. Pyrrhotite and the remanent magnetization of SNC meteorites: a changing perpective on Martian magnetism. Earth Planet. Sci. Lett., 1-12.

Romaneck, C.S., Grady, M.M., Wright, I.P., Mittlefehldt, D.W., Sock1, R.A., Pillinger, C.T., Gibson Jr., E.K., 1994. Record of fluid-rock interactions on Mars from the meteorite ALH84001. Nature 372 (6507), 655-957.

Schwertmann, U., 1985. The effect of pedogenic environment on iron oxide minerals. Adv. Soil Sci. 1, 171-200.

Schwertmann, U., Cornell, R.M., 1991. Iron Oxides in the Laboratory. Preparation and Characterization. VCH Publishers. Inc., New York, USA, 137pp.

Schwertmann, U., Murad, E., 1983. Effect of $\mathrm{pH}$ on the formation of goethite and hematite from ferrihydrite. Clays Clay Miner 31 (4), $277-284$.

Schwertmann, U., Friedl, J., Stanjek, H., 1999. From Fe(III) ions to ferrihydrite and then to hematite. J. Colloid Interface Sci. 209, 215-223.

Shean, D.E., Head, J.W., Marchant, D.R., 2005. Origin and evolution of a cold-based tropical mountain glacier on Mars: the Pavonis Mons fanshaped deposit. J. Geophys. Res. 110 (E05001).

Sherman, D.M., Burns, R.G., Mee Burns, V., 1981. Assessment of ferric iron oxide minerals likely to occur on Mars. Lunar Planet. Sci. XII, 970-972.

Singer, R.B., 1981. Spectral constraints on iron-rich smectites as abundant constituents of Martian soils. Lunar Planet. Sci. 12, 996-998.

Singer, R.B., 1982. Spectral evidence for the mineralogy of high-albedo soils and dust on Mars. J. Geophys. Res. 87 (B12), 10159-10168.

Smith, D.E., Zuber, M.T., Solomon, S.C., Phillips, R.J., Head, J.W., Garvin, J.B., Banerdt, W.B., Muhleman, D.O., Pettengill, G.H., Neumann, G.A., Lemoine, F.G., Abshire, J.B., Aharonson, O., Brown, C.D., Hauck, S.A., Ivanov, A.B., McGovern, P.J., Zwally, H.J., Duxbury, T.C., 1999. The global topography of Mars and implications for surface evolution. Science 284, $1495-1503$

Squyres, S.W., Arvidson, R.E., Bell III, J.F., Brückner, J., Cabrol, N.A., Calvin, W., Carr, M.H., Christensen, P.R., Clark, B.C., Crumpler, L., Des Marais, D.J., d'Uston, C., Economou, T., Farmer, J., Farrand, W., Folkner, W., Golombeck, M., Gorevan, S., Grant, J.A., Greeley, R., Grotzinger, J., Haskin, L., Herkenhoff, K.E., Hviid, S., Johnson, J., Klingelhöfer, G., Knoll, A.H., Landis, G., Lemmon, M., Li, R., Madsen, M.B., Malin, M.C., McLennan, S.M., McSween Jr., H.Y., Ming, D.W., Moersch, J., Morris, R.V., Parker, T., Rice Jr., J.W., Richter, L., Rieder, R., Sims, M., Smith, M., Smith, P., Soderblom, L.A., Sullivan, R., Wänke, H., Wdowiak, T., Wolff, M., Yen, A., 2004a. The opportunity rover's Athena science investigation at the Meridiani Planum, Mars. Science 306, 1698-1703.

Squyres, S.W., Gotzinger, J.P., Arvidson, R.E., Bell III, J.F., Calvin, W., Christensen, P.R., Clark, B.C., Crisp, J.A., Farrand, W.H., Herkenhoff, K.E., Johnson, J.R., Klingelhöfer, G., Knoll, A.H., McLennan, S.M., McSween Jr., H.Y., Morris, R.V., Rice Jr., J.W., Rieder, R., Soderblom, L.A., 2004b. In situ evidence for an ancient aqueous environment at Meridiani Planum, Mars. Science 306, $1709-1714$

Squyres, S.W., Knoll, A.H., 2005. Sedimentary rocks at Meridiani Planum: origin, diagenesis, and implications for life on Mars. Earth Planet. Sci. Lett. 240, 1-10.

Squyres, S.W., Arvidson, R.E., Blaney, D.L., Clark, B.C., Crumpler, L., Farrand, W.H., Gorevan, S., Herkenhoff, K.E., Hurowitz, J., Kusack, A., McSween Jr., H.Y., Ming, D.W., Morris, R.V., Ruff, S.W., Wang, A., Yen, A., 2006. Rocks of the Columbia Hills. J. Geophys. Res. 111 (E02S11).
Sracek, O., Choquette, M., Gélinas, P., Lefebvre, R., Nicholson, R.V., 2004. Geochimical characterization of acid mine drainage from a waste rock pile, Mine Doyon, Québec, Canada. J. Contam. Hydrol. 69, 45-71.

Tang, Y., Chen, Q., Huang, Y., 2006. Early Mars may have had a methanol ocean. Icarus $180,88-92$.

Tokano, T., Bish, D.L., 2005. Hydration state and abundance of zeolites on Mars and the water cycle. J. Geophys. Res. 110 (E12S08).

Tardy, Y., Nahon, D., 1985. Geochemistry of laterites, stability of Algoethite, Al-hematite and $\mathrm{Fe}^{3+}$ kaolinites in bauxites and ferricretes. Amer. J. Sci. 285, 865-903.

Tardy, Y., Bardossy, G., Nahon, D., 1988a. Fluctuations de l'activité de l'eau et successions de minéraux hydratés et déshydratés au sein des profils latéitiques ferrugineux et bauxitiques. C.R. Acad. Sci. Paris Ser. II 307, 753-759.

Tardy, Y., Mazaltarim, D., Boeglin, J.L., Roquin, C., Pion, J.C., Paquet, H., Millot, G., 1988b. Lithodependence and homogenization of mineralogical and chemical-composition in lateritic ferricretes. C. R. Acad. Sci. Paris-Sci. TerreSér. II 307 (16), 1765-1772.

Torrent, J., Guzman, R., Parra, M.A., 1982. Influence of relative humidity on the crystallization of $\mathrm{Fe}(\mathrm{III})$ oxides from ferrihydrite. Clays Clay Miner 30 (5), 337-340.

Tosca, N.J., McLennan, S.M., 2006. Chemical divides and evaporite assemblages on Mars. Earth Planet. Sci. Lett. 241, 21-31.

Tosca, N.J., McLennan, S.M., Lindsley, D.H., Schoonen, M.A.A., 2004. Acid-sulfate weathering of synthetic Martian basalt: the acid fog model revisited. J. Geophys. Res. 109 (E05003).

Tosca, N.J., McLennan, S.M., Clark, B.C., Grotzinger, J.P., Hurowitz, J.A., Knoll, A.H., Schröder, C., Squyres, S.W., 2005. Geochemical modeling of evaporation processes on Mars: insight from the sedimentary record at Meridiani Planum. Earth Planet. Sci. Lett. 240, 122-148.

Toulmin III, P., Clark, B.C., Baird, A.K., Keil, K., Rose Jr., H.J., 1976. Preliminary results from the Viking X-ray fluorescence experiments: the first sample from Chryse Planitia, Mars. Science 194 (4260), 81-84.

Toulmin, P., Baird, A.K., Clark, B.C., Keil, K., Rose Jr., H.J., Christian, R.P., Evans, P.H., Kelliher, W.C., 1977. Geochemical and mineralogical interpretation of the viking inorganic chemical results. J. Geophys. Res. 82 (28), 4625-4634.

Towe, K.M., 1980. Feroxyhyte on Mars? Nature 288, 196.

Treiman, A.H., Barrett, R.A., Gooding, J.L., 1993. Preterrestrial aqueous alteration of the Lafayette (SNC) meteorite. Meteoritics 28, 86-97.

Treiman, A.H., Amundsen, H.E.F., Blake, D.F., Bunch, T., 2002. Hydrothermal origin for carbonate globules in Martian meteorite ALH84001: a terrestrial analogue from Spitsbergen (Norway). Earth Planet. Sci. Lett. 204, 323-332.

Tsapin, A.I., Goldfeld, M.G., McDonald, G.D., Nealson, K.H., Moskovitz, B., Solheid, P., Kemmer, K.M., Kelly, S.D., Orlandini, K.A., 2000. Iron(VI): hypothetical candidate for the Martian oxidant. Icarus $147,68-78$.

Valley, J.W., Eiler, J.M., Graham, C.M., Gibson, E.K., Romanek, C.S., Stolper, E.M., 1997. Low-temperature carbonate concretions in the Martian meteorite ALH84001: evidence from stable isotopes and mineralogy. Science 275 (5306), 1633-1638.

Vaniman, D.T., Bish, D.L., Chipera, S.J., Fialips, C.I., Carey, J.W., Feldman, W.C., 2004. Magnesium sulphate salts and the history of water on Mars. Nature 431, 663-665.

Vlag, P., Rochette, P., Dekkers, M.J., 1996. Some additional hysteresis parameters for a natural (titano)magnetite with known grain size. Geophys. Res. Lett. 23 (20), 2803-2806.

Wade, M.L., Agresti, D.G., Wdowiak, T.J., Armendarez, L.P., Farmer, J.D., 1999. A Mössbauer investigation of iron-rich terrestrial hydrothermal vent system: lessons for Mars exploration. J. Geophys. Res. 104 (E4), 8489-8507.

Wang, A., Haskin, L.A., Squyres, S.W., Jolliff, B.L., Crumpler, L., Gellert, R., Schröder, C., Herkenhoff, K., Hurowitz, J., Tosca, N.J., Farrand, W.H., Anderson, R., Knudson, A.T., 2006a. Sulfate 
deposition in subsurface regolith in Gusev crater, Mars. J. Geophys. Res. 111 (E02S17).

Wang, A., Korotev, R.L., Jolliff, B.L., Haskin, L.A., Crumpler, L., Farrand, W.H., Herkenhoff, K.E., de Souza Jr., P., Kusack, A.G., Hurowitz, J.A., Tosca, N.J., 2006b. Evidence of phyllosilicates in Wooly Patch, an altered rock encountered at West Spur, Columbia Hills, by the Spirit rover in Gusev crater, Mars. J. Geophys. Res. 111 (E02S16).

Wänke, H., Dreibus, G., Jagoutz, E., Mukhin, L.M., 1992. Volatiles on Mars: the role of $\mathrm{SO}_{2}$ (abstract). Lunar Planet. Sci. Conf. XXIII, 1489-1490.

Warren, P.H., 1987. Mars regolith versus SNC meteorites: possible evidence for abundant crustal carbonates. Icarus 70, 153-161.

Wdowiak, T.J., Klingelhöfer, G., Wade, M.L., Nuñez, J.I., 2003. Extracting science from Mössbauer spectroscopy on Mars. J. Geophys. Res. 108 (E12), \#8097.

Weldon, R.J., Thomas, W.M., Boslough, M.B., Arhens, T.J., 1982. Shockinduced color changes in nontronite: implications for the Martian fines. J. Geophys. Res. 97 (B12), 10102-10114.

Wentworth, S.J., Gooding, J.L., 1994. Carbonates and sulfates in the Chassigny meteorite: further evidence for aqueous chemistry on the SNC parent planet. Meteoritics 29, 860-863.

Wyatt, M.B., McSween Jr., H.Y., 2002. Spectral evidence for weathered basalt as an alternative to andesite in the northern lowlands of Mars. Nature 417, 263-266.

Wyatt, M.B., McSween Jr., H.Y., 2003. Reply to Hamilton et al., 2003. Nature 421, 412-413.
Wyatt, M.B., McSween Jr., H.Y., Tanaka, K.L., Head III, J.W., 2004. Global context for rock types and surface alteration of Mars. Geology 32 (8), 654-658.

Yen, A.S., Murray, B., Rossman, G.R., Grunthaner, F.J., 1999. Stability of hydroxylated minerals on Mars: a study on the effects of exposure to ultraviolet radiation. J. Geophys. Res. 104 (E11), 27031-27041.

Yen, A.S., Kim, S.S., Hecht, M.H., Frant, M.S., Murray, B., 2000. Evidence that the reactivity of the Martian soils is due to superoxide ions. Science 289 (5486), 1909-1912.

Yen, A.S., Gellert, R., Schröder, C., Morris, R.V., Bell III, J.F., Knudson, A.T., Clark, B.C., Ming, D.W., Crisp, J.A., Arvidson, R.E., Blaney, D., Brückner, J., Christensen, P.R., DesMarais, D.J., de Souza Jr., P.A., Economou, T.E., Ghosh, A., Hahn, B.C., Herkenhoff, K.E., Haskin, L.A., Hurowitz, J.A., Joliff, B.L., Johnson, J.R., Klingelhöfer, G., Madsen, M.B., McLennan, S.M., McSween Jr., H.Y., Richter, L., Rieder, R., Rodionov, D., Soderblom, L., Squyres, S.W., Tosca, N.J., Wang, A., Wyatt, M., Zipfel, J., 2005. An integrated view of the chemistry and mineralogy of Martian soils. Nature 436, 49-54.

Zent, A.P., Quinn, R.C., 1995. Simultaneoux adsoprtion of $\mathrm{CO}_{2}$ and $\mathrm{H}_{2} \mathrm{O}$ under Mars-like conditions and application to the evolution of the Martian climate. J. Geophys. Res. 100 (E3), 5341-5349.

Zent, A.P., Howard, D.J., Quinn, R.C., 2001. $\mathrm{H}_{2} \mathrm{O}$ adsorption on smectites: application to the diurnal variation of $\mathrm{H}_{2} \mathrm{O}$ in the Martian atmosphere. J. Geophys. Res. 106 (7), 14667-14674.

Zolotov, M.Y., Shock, E.L., 2005. Formation of jarosite-bearing deposits through aqueous oxidation of pyrite at Meridiani Planum, Mars. Geophys. Res. Lett. 32 (L21203). 